\title{
An Analysis of the Reliability and Design Optimization of Aluminium Ribbon Bonds in Power Electronics Modules Using Computer Simulation Method
}

\author{
Kenneth Chimezie Nwanoro*, Hua Lu, Chunyan Yin, Chris Bailey \\ Computational Mechanics and Reliability Group, Queen Mary Building, University of \\ Greenwich, London, UK, SE10 9LS.33 \\ * Corresponding Author: $\underline{\text { K.C.Nwanoro@greenwich.ac.uk }}$
}

\begin{abstract}
Ribbon bonding technique has recently been used as an alternative to wire bonding in order to improve the reliability, performance and reduce cost of power modules. In this work, the reliability of aluminium and copper ribbon bonds for an Insulated Gate Bipolar Transistors (IGBT) power module under power cycling is compared with that of wire bonds under power and thermal cycling loading conditions. The results show that a single ribbon with a cross section of $2000 \mu \mathrm{m} \times 200 \mu \mathrm{m}$ can be used to replace three wire bonds of $400 \mu \mathrm{m}$ in diameter to achieve similar module temperature distribution under the same power loading and ribbon bonds have longer lifetime than wire bonds under cyclic power and thermal cycling conditions. In order to find the optimal ribbon bond design for both power cycling and thermal cycling conditions, multi-objective optimization method has been used and the Pareto optimal solutions have been obtained for trade off analysis.
\end{abstract}

Keywords

Reliability, Wire/ribbon bond, Power electronics, Power cycling, Thermal cycling, Multiobjective optimization.

\section{Introduction}

The applications of power electronics systems using semiconductors such as insulated gate bipolar transistors (IGBT) and metal oxide semiconductors field effect transistors (MOSFET) are wide ranging and continuously increasing. They are used in drive systems such as elevators, subways, locomotives, electric vehicles to industrial pumps, household appliances and in power generation, conversion and transmission. There is a constant demand for high power density power electronics with higher switching frequency. Other desired requirements include reduced weight and volume, lower cost, high reliability and ability to operate at increasing severe operating conditions. To meet such demands, designers and manufacturers in the power electronics industry are devising new packaging methods and materials. Some of these include new electrical interconnect designs that have low on-state resistance [1], use of sintered silver joints, integrated packaging and the use of high temperature operating materials such as wide band gap semiconductors. For electrical interconnection, one of the techniques that has been proposed is the use of aluminium ( $\mathrm{Al}$ ) ribbon bonds interconnections in power modules to replace the conventional $\mathrm{Al}$ wire bonds. 
Ribbon bonds are not entirely new technology as they have been used extensively for high frequency applications for example in optical and optoelectronic devices [2]. They have also been used for power electronic applications such as in compact DC- DC MOSFET converters like $D^{2} \mathrm{PAK}$ and quad-flat-no lead (QFN) packages [3]. However, recently, their use in the IGBT power electronic module such as in Toyota Prius 2010 model [4] has been gaining attention. The advantages of ribbon over conventional round wire has been discussed in [5] and references therein. One of the reasons ribbon is gaining attention is because a single ribbon usually has a lower electrical resistivity than a single wire of the same length. Therefore a higher current handling capability. This allows a single ribbon to replace a number of wires in order to meet the same current rating requirement or to achieve the same conducting resistance.

\section{Wire bond failure modes}

The wire bond is prone to two major failure modes. Figure 1 show the locations of the heel crack, bond crack and bond wire lift-off failure. The two failure modes occur at its two weakest point- the bond tail (foot) and the bond heel, with the bond wire lift-off being the most frequent.

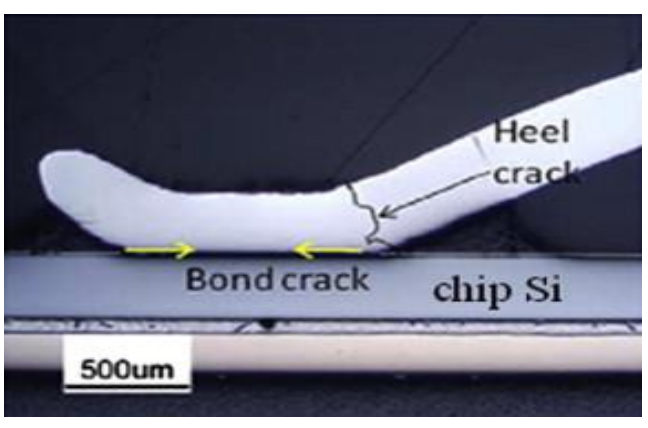

(a)

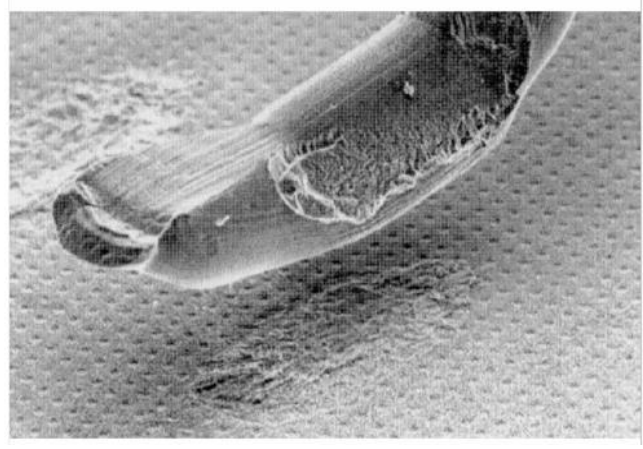

(b)

Figure 1. (a) Locations of bond wire heel and bond crack [6]. (b). Wire bond lift-off failure which is the result of bond crack [7].

The wire bond failure is mostly due to thermo-mechanical fatigue from temperature swings caused by environmental conditions, power dissipation from the power chips during switching and conduction, and ohmic heating in the wire itself. When temperature changes in the power module, shear stress at the interface of the bond wire and the bond pad develops because of coefficient of thermal expansion CTE mismatch between the Al bond wire and the silicon chip. This stress results in the initiation and propagation of cracks near the interface and eventually leads to wire bond lift-off failure [8]. Also due to the repeated flexure of the wire during the thermal swing, cracks may develop at the bond heel which leads to heel cracking failure [9]. The effect of wire bond failure results in changes in either contact resistance value or internal distribution of current leading to increased temperature above the safe operating area (SOA) of the power device. Some ribbon bond thermo-mechanical behaviour studies in the literature for different applications and their limitations has been presented in [5].

Meyyappan [10] studied the influence of wire geometry on its reliability using the beam curve theory and minimization of the potential energy. The study used thermal cycling only and focused on microelectronics wire bonds where power/current density is usually low. Celnikier 
et al [6] investigated the loop height variations (displacement) of ribbon bonds using analytical solutions of thermal cycling. The geometric effect of bonding constraints under power cycling has not been established and correlated with that of thermal cycling to enable effective design optimization of the wire/ribbon bond. In general, information of what would help the optimal design of ribbon bond in power modules is scarce and this work is to address this issue.

Despite of the above mentioned works, the reliability of the ribbon bonds based on heat generation from joule heating and cyclic power loss in the power device especially for IGBT power modules applications has not been fully investigated yet. Design optimization of ribbon bond considering power cycling has not been carried out. In an earlier work by the authors of this paper, the thermo-mechanical behaviors of ribbon bonds under simplified power cycling loading conditions were analyzed and compared with those of conventional wire bonds, and it was concluded that ribbon bonds are more reliable than wire bonds under the given conditions [5]. In the present work, a more realistic loading conditions are used in the thermal mechanical simulation. Copper ribbon bonds have also been considered as potential replacement for $\mathrm{Al}$ wire/ribbon bonds and the reliability of $\mathrm{Cu}$ ribbon bonds has been compared with $\mathrm{Al}$ ribbon bonds. Furthermore, parametric reliability analysis has been carried out which can be used for design optimization. To find the trade-off relationship between the objective of keeping the maximum temperature in the device low and that of keeping the mechanical fatigue damage low in ribbon bonds, a multi-objective optimization technique has been used in this work.

\section{Methodology}

Two IGBT power modules models shown in the Figure 2 are studied using Finite Element Method (FEM). The IGBT power module dimensions are given in Table 1. The layout and characteristics of these power module models are similar to that of the Powerex IGBT halfbridge module CM150DU-24NFH [11]. The power transistors and diodes in the IGBT modules are similar in characteristics and dimensions to that of commercial ABB IGBT Die 5SMY 12M1280 [12] and Diode-Die 5SLY 12J1200 [13] respectively.

Based on cross-sectional considerations, a single ribbon of specific dimensions can replace several number of wires of a certain diameter for equivalent current carrying capability $[1,14]$. In this work, the case of replacing three $400 \mu \mathrm{m}$ aluminium wires with a single ribbon of $2000 \mu \mathrm{m}$ x $200 \mu \mathrm{m}$ in cross-section has been studied. The models are shown in Figures 2.

Figure 3 shows the schematic of an IGBT power module. It can be seen that an IGBT power module is made of several layers of different materials. The power semiconductor devices such as IGBT and diodes are mounted on an insulated substrate. The substrate is usually direct bonded copper (DBC). Solder materials are used as attachment material. The DBC is made of a ceramic substrate such as aluminium nitride (AIN) sandwiched between two copper layers. The DBC is mounted on a base plate using solder material as interconnect. Wire bonds are used for electrical connection of the power devices to other conductors. 


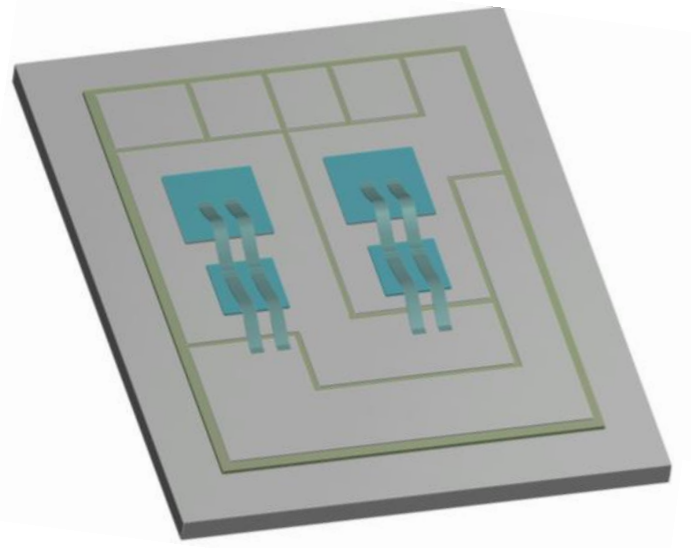

(a)

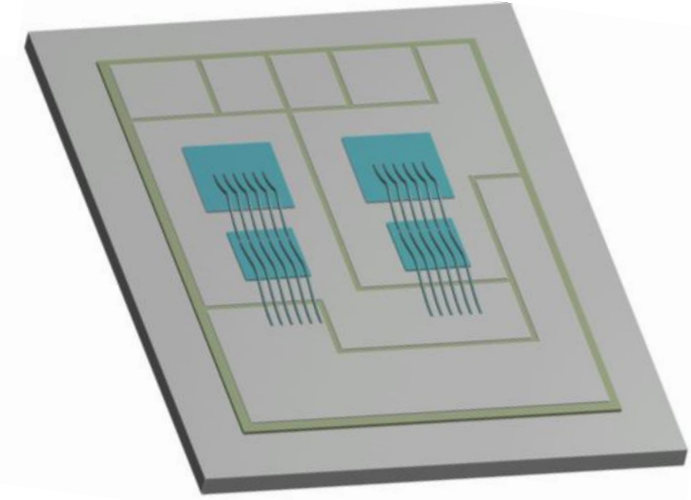

(b)

Figure 2. (a) IGBT module with ribbon bonds

(b). IGBT module with wire bond

\begin{tabular}{|l|l|l|l|l|l|}
\hline & Length/Span & Thickness & Width & Diameter & Loop height \\
\hline IGBT & 13.5 & 0.14 & 13.5 & - & - \\
\hline Diode & 10 & 0.35 & 10 & - & - \\
\hline Ribbon & 13.75 & 0.2 & 2 & - & 2.5 \\
\hline Wire & 13.75 & 0.4 & - & 0.4 & 2.5 \\
\hline Top DBC Cu & 75 & 0.3 & 55 & - & - \\
\hline DBC AlN & 78 & 0.6 & 58 & - & - \\
\hline Bottom DBC Cu & 75 & 0.3 & 55 & - & - \\
\hline Bottom solder & 75 & 0.2 & 55 & - & - \\
\hline Base plate & 94 & 3 & 74 & - & - \\
\hline
\end{tabular}

Table 1. Dimensions of the model geometry ( $\mathrm{mm})$

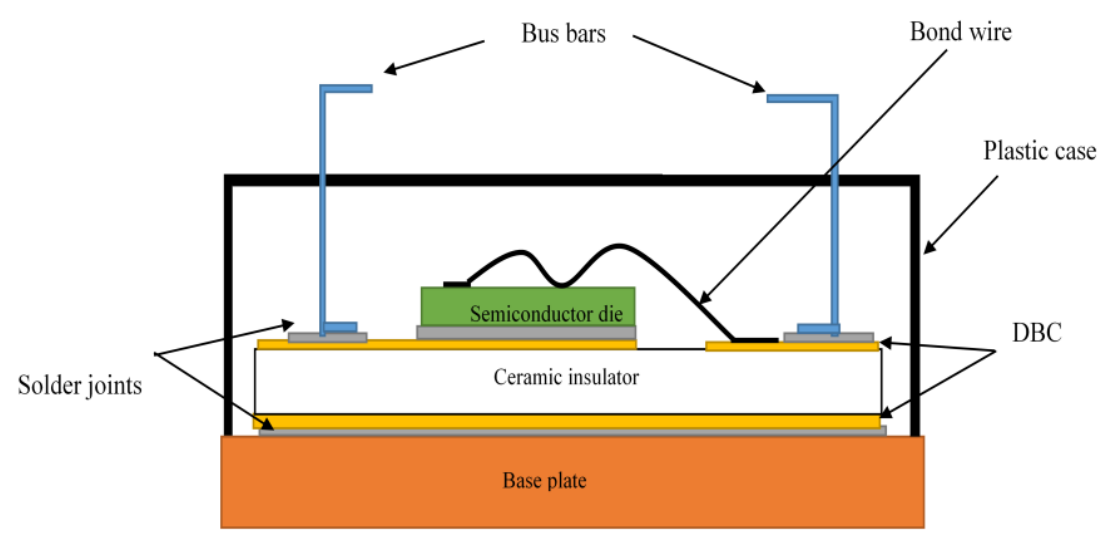

Figure 3: Schematic of IGBT power module 


\subsection{Finite element analysis (FEA) simulation}

Thermal-mechanical analysis of the power module models has been carried out using ANSYS V. 17.1, a commercial multi-physics FEA software package. Power cycling loading is realized by switching heat generation in the module on and off. A power cycling test circuit can be either AC or DC circuit depending on the current used for the testing. Different power cycling circuit and testing conditions in the literature were outlined in [15].

In this simulation, the IGBTs are assumed switched on permanently during the power cycling. The current load is taken to be from a constant DC source switched on and off by external circuit. Experimentally, in this type of power cycling set-up condition, the IGBT gate is permanently set to a constant value. The gate voltage $V_{G E}$ must be set to a value higher but close enough to the gate-emitter threshold voltage $V_{G E(t h)}[7,16]$ to ensure that same current and temperature swing is obtained in the IGBTs. So the diodes were not loaded and therefore no diode power loss and no switching losses. This simulation assumption is similar to the experimental power cycling tests using DC circuits such as in [7]. However, with the exceptions of current load values, heating/cooling times. Initial setting of lower and higher temperature limits and adjusting cooling systems were not used in this study. The turn on and turn off of the source current is assumed continuous until a cyclic equilibrium temperature distribution in the power module is achieved. This is based on the assumption that the damage progress (i.e. the crack growth rate per cycle) in the wire bond will remain relatively constant at this cyclic condition. And also to justify the use of cyclic equivalent plastic strain in the fatigue life prediction. Therefore, this testing condition is to test only the reliability of the wire/ribbon bonding configuration in the power module due to temperature swing. A continuous cooling is also assumed.

Since the study is focused on the wire/ribbon bonding failure, the cycle period should be within seconds as described in many IGBT power module power cycling tests such as in $[17,18]$. This is because, cycle period less than 1 minute is more sensitive to wire bond fatigue. Therefore a constant turn-on (heating) and turn-off (cooling) times of $4 \mathrm{~s}$ and $11 \mathrm{~s}$ respectively were used giving a 15 s cycle period. Changing this turn on and turn off times, can only reduce or increase the number of cycles to achieve a cyclic thermal equilibrium. It will also either increase or decrease the junction and case temperature swings. However, if temperature swing in the power module is within the device safe operating area, similar damage/ failure mode will be recorded i.e. bond lift off and/or heel crack from wear out/fatigue and may be cracking of the chip-DBC solder joint.

Different cooling methods and systems have been used for power cycling tests and simulations in the literature. The cooling method chosen is often driven by the kind of failure mode anticipated and how fast to reach the intended temperature swing. Some cooling methods such as forced air cooling, liquid cooling and constant base plate or heat sink temperature (isothermal) have been used both experimentally and in simulations $[17,18,19,20]$. However, equivalent convective heat transfer coefficient which often represents a forced air or water cooling is more widely used by researchers than a fixed temperature boundary condition in simulation. This is because it provides a non-uniform temperature distribution in the power module, hence more realistic than a fixed uniform temperature boundary condition.

Therefore in this study, at the bottom of the baseplate, an equivalent convective heat transfer coefficient value is assumed to be $500 \mathrm{~W} / \mathrm{m}^{2} \mathrm{~K}$ throughout the power cycling duration and the ambient temperature is fixed at $293 \mathrm{~K}$. The assumed equivalent convective heat transfer 
coefficient value is close to range of values for forced water convection cooling reported in [20]. The other surfaces are assumed adiabatic as has also been assumed in many other simulation studies in the literature such as in [17,21].This means that the model is assumed covered with epoxy moulding compound and plastic encapsulation. These materials have much lower thermal conductivities when compared with materials in the power module layers. Hence, their effects on the thermal analysis is negligible [21]. Other convective surfaces (top and sides) and radiation are neglected. Top and sides of the model can be assumed to have natural convective heat transfer coefficient (still air) which is very small $5 \mathrm{~W} / \mathrm{m}^{2} \mathrm{~K}$ [23] compared with the equivalent convective heat transfer coefficient at base plate where most of the heat is released. Therefore, the adiabatic assumption for the top and sides surfaces.

Two loading conditions are applied. In the first one the heat generation is applied in the IGBT chips only. In this condition, the only heat source is the conduction loss in the semiconductor. In the second loading condition, in addition to chip heat generation, joule heating in the wires/ribbons is considered. Because copper will be investigated as an alternative to aluminium as the ribbon material, the total number of cases is 6 , which are described in Table 2.

In the FEA simulation, the whole structure is assumed to be free-standing and only constraints that prevent rigid body movements are applied. The whole model is assumed stress-free at $293 \mathrm{~K}$.

\begin{tabular}{|c|c|c|c|c|c|c|}
\hline Case No & Case 1 & Case 2 & Case 3 & Case 4 & Case 5 & Case 6 \\
\hline Condition & $\begin{array}{l}\text { Al ribbon } \\
\text { bond } \\
\text { without } \\
\text { joule } \\
\text { heating }\end{array}$ & $\begin{array}{l}\text { Al Wire } \\
\text { bond } \\
\text { without } \\
\text { joule } \\
\text { heating }\end{array}$ & $\begin{array}{l}\text { Al ribbon } \\
\text { bond } \\
\text { with joule } \\
\text { heating }\end{array}$ & $\begin{array}{l}\text { Al Wire } \\
\text { bond with } \\
\text { joule } \\
\text { heating }\end{array}$ & $\begin{array}{l}\mathrm{Cu} \text { ribbon } \\
\text { bond } \\
\text { without } \\
\text { joule } \\
\text { heating }\end{array}$ & $\begin{array}{l}\mathrm{Cu} \text { ribbon } \\
\text { bond } \\
\text { with joule } \\
\text { heating }\end{array}$ \\
\hline
\end{tabular}

Table 2. Cases and loading conditions

Considering the size of the models, the number of simulations required and to achieve mesh convergence, a sub-modelling technique was adopted for the structural analysis. Three stages are required in the sub-modelling technique. Initially, the full model with relatively coarse mesh was analysed (Figure 4a for wire bond). Then a sub-model with finer mesh (Figure 4b for wire bond) was built to represent the section of interest (wire and ribbon bonds). Finally, the full model's nodal degrees of freedom solutions along the sub-model boundaries were used as the boundary conditions for the sub-model. Then, the sub-model was analysed. Since submodelling technique is based on St Venant's principle, it is required that stress along the cut boundary be close to that of the coarse model [23]. 


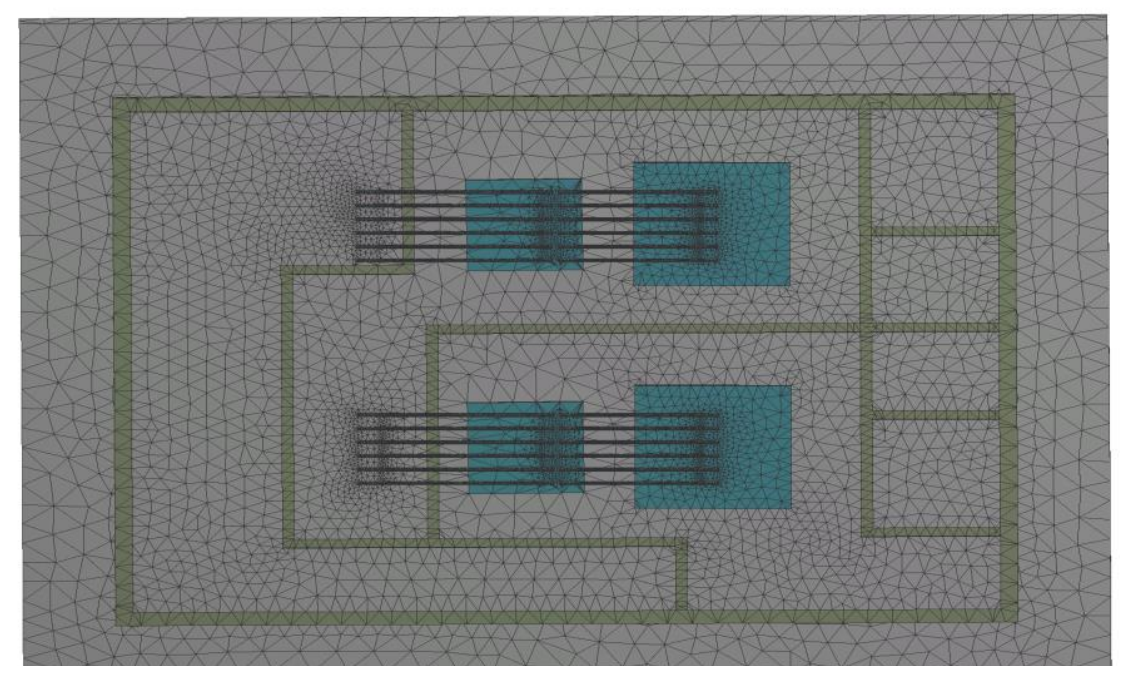

(a)

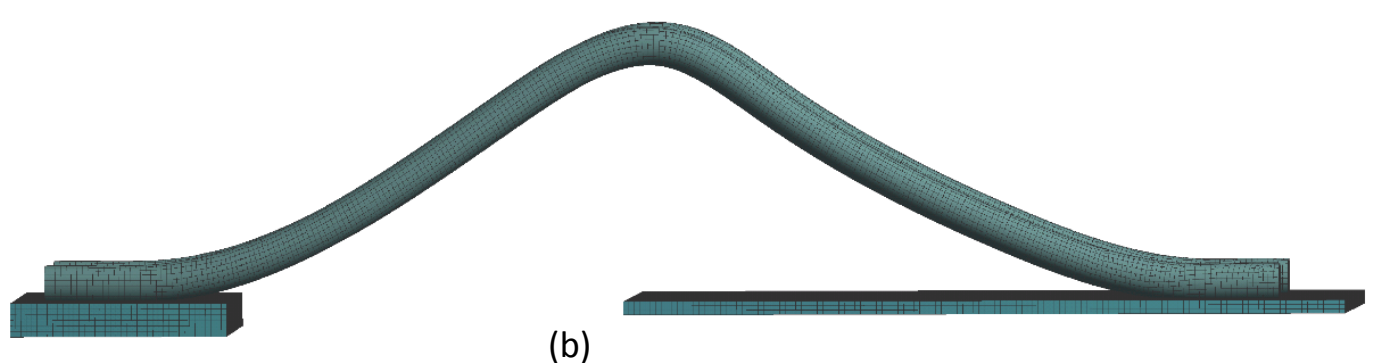

Figure 4. (a) Coarse mesh for the global model (wire bond). (b) A fine mesh of the wire bond sub-model

The solder material (lead free solder $96.5 \mathrm{Sn} 3.5 \mathrm{Ag}$ ) has been modelled as viscoplastic material using the Anand's model. The Copper and aluminium materials are modelled as elastic-plastic materials. Other materials are assumed to be linear-elastic. The material properties used in this study are listed in Table 3. They are typical values that can be found in [24-26]. The parameters for the Anand's model [27] are given in Table 4.

In the simulation, power losses calculated using data sheet values and equations presented in section 3.2 are applied to the IGBT. 


\begin{tabular}{|c|c|c|c|c|c|}
\hline $\begin{array}{c}\text { Material } \\
\text { properties }\end{array}$ & Silicon & Al & Copper & $\begin{array}{c}\text { Aluminium } \\
\text { Nitride }\end{array}$ & Solder \\
\hline $\mathrm{E}(\mathrm{GPa})$ & 113 & 70 & 103.42 & 310 & $54.05-0.19 \mathrm{~T}$ \\
\hline Poisson's ratio & 0.29 & 0.33 & 0.3 & 0.24 & 0.4 \\
\hline $\mathrm{CTE}\left(10^{-6} / \mathrm{K}\right)$ & 2.6 & 23.1 & 17 & 5.6 & $21.85+0.02039 \mathrm{~T}$ \\
\hline $\mathrm{k}(\mathrm{W} / \mathrm{mK})$ & 150 & 235 & 400 & 160 & 54 \\
\hline$\rho\left(\mathrm{kg} / \mathrm{m}^{3}\right)$ & 2330 & 2700 & 8930 & 3300 & 8400 \\
\hline $\mathrm{C}(\mathrm{J} / \mathrm{kg} \cdot \mathrm{K})$ & 729 & 950 & 400 & 740 & 150 \\
\hline $\begin{array}{c}\text { Electrical } \\
\text { resistivity }(\Omega . m)\end{array}$ & 0.0001 & $2.65 \times 10^{-8}$ & $1.7 \times 10^{-8}$ & $1 \times 10^{14}$ & $1.3 \times 10^{-1}$ \\
\hline $\begin{array}{c}\text { Yield stress } \\
(\mathrm{MPa})\end{array}$ & - & $31[16]$ & $98.7[16]$ & - & - \\
\hline $\begin{array}{c}\text { Tangent modulus } \\
(\mathrm{MPa})\end{array}$ & - & $45.7[16]$ & $1000[16]$ & - & - \\
\hline
\end{tabular}

Table 3. Material properties.

E is the Young's modulus, $\mathrm{k}$ is the material thermal conductivity, $\rho$ is the density, $C$ is the specific heat capacity and $\mathrm{T}$ is temperature in $\mathrm{K}$.

\begin{tabular}{|l|l|l|l|l|l|l|l|l|l|}
\hline Parameters & $S_{o}(\mathrm{MPa})$ & $\begin{array}{l}\mathrm{Q} / \mathrm{R} \\
(\mathrm{K})\end{array}$ & $\mathrm{A}\left(S^{-1}\right)$ & $\xi$ & $m_{0}$ & $h_{0}(\mathrm{MPa})$ & $\hat{s}(\mathrm{MPa})$ & $\mathrm{n}$ & $\mathrm{a}$ \\
\hline Solder & 39.09 & 8900 & $2.23 \times 10^{4}$ & 6 & 0.182 & 3321.15 & 73.81 & 0.0018 & 1.82 \\
\hline
\end{tabular}

Table 4. Material parameters for Anand's viscoplastic model

\subsection{Power losses}

The power losses in the IGBTs were only conduction losses with no switching losses (no device switching action).The conduction losses are calculated using the following equations:

$$
\begin{gathered}
P_{c o n d-I G B T}=V_{C E} I_{C} \\
V_{C E}=V_{C E o}+R_{o} I_{C}
\end{gathered}
$$

$P_{\text {cond-IGBT }}$ is the IGBT conduction losses. $V_{C E}$ is the IGBT collector-emitter saturation voltage, $I_{C}$ is the collector on-state current, $R_{O}$ is IGBT on-resistance. $V_{C E O}$ is the zero current value of the $V_{C E}$.

The on resistance is estimated by linear extrapolation (Figure 5) of a typical on state characteristics from the data sheet in this case [12].

$$
R_{o}=\frac{V_{C E 2}-V_{C E 1}}{I_{C 2}-I_{C 1}}
$$




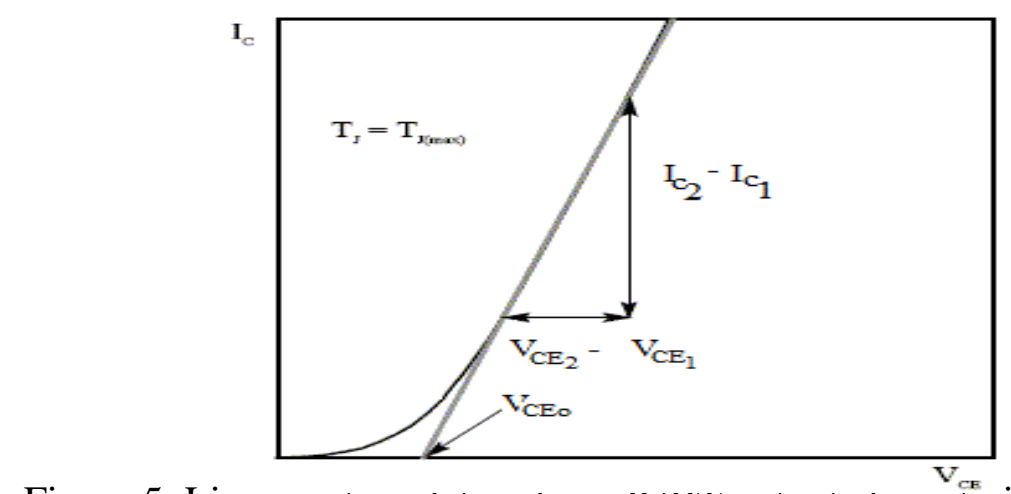

Figure 5. Linear extrapolation trom IGB I output characteristic

The joule heating (ohmic heating) in the wire/ribbon bond is calculating using (4).

$$
\mathrm{Q}=I^{2} \mathrm{R}=I^{2} \rho_{o} L / A
$$

where: $\mathrm{Q}$ is the wire/ribbon joule heat, $\mathrm{I}$ is the current, $\mathrm{L}$ is the wire/ribbon span, $\mathrm{A}$ is the crosssectional area and $\rho_{o}$ is the electrical resistivity.

In this work, 100 amps collector current is applied for each IGBT. Based on equation 2 and making use of equation 3 and data datasheet in [12], the calculated $V_{C E}$ is $1.9 \mathrm{~V}$. From equation 1 and $V_{C E}$ value, the conduction power loss for each IGBT is $190 \mathrm{~W}$.

\subsection{Thermo-Mechanical analysis}

In FEA, thermo-mechanical analysis can be performed as direct (fully) coupled phenomenon by solving simultaneously the strain-heat transfer (5) and temperature/displacement (6) equation using a coupled element while considering material nonlinearities.

$$
\begin{array}{r}
\nabla .(k \nabla T)-\rho C(d T / d t)-(3 \lambda+2 \mu) \dot{\varepsilon}_{i i} \alpha T_{0}=-\dot{q} \\
\mu u_{i, k k}+(\lambda+\mu) u_{k, k i}-(3 \lambda+2 \mu) \alpha \Delta T=0
\end{array}
$$

Where $\dot{q}$ the heat generation rate, $\mathrm{u}$ is the displacement, $\lambda$ an $d \mu$ are the Lame's constants. $\Delta T$ is the temperature change from a zero strain reference temperature. Alternatively, sequentially coupled thermal-stress analysis (used in this study) can be used. In this case, initially the temperature distribution in the power module as a result of the heat dissipation and joule heating is computed for a transient thermal analysis using (7).

$$
\nabla .(k \nabla T)+\dot{q}=\rho C(d T) / d t
$$

Then, the temperature distribution is used to compute thermal strain vector $\varepsilon_{t h}(8)$ as a result of temperature change from a reference state.

$$
\varepsilon_{t h}=\{\alpha \Delta T\}
$$

The thermal strain is then used to compute the thermal load vector $F_{t h}(9)$

$$
F_{t h}=\int B^{T} D\{\alpha \Delta T\} d v
$$


$\mathrm{B}$ is the derivatives of element shape functions, D is linear isotropic fourth order Hooke's tensor, $\alpha$ is the CTE.

\subsection{Life Prediction model}

For interconnect that experiences cyclic plastic deformation which leads to low cycle fatigue, its life time $N_{f}$, which is defined as the number of cycles to failure, can be estimated using the Coffin-Manson equation [28] given in (10).

$$
\left(2 N_{f}\right)^{c}=\frac{\Delta \varepsilon_{p}^{-}}{2 \epsilon_{f}^{\prime}}
$$

Where the constants $\epsilon_{f}^{\prime}$ and $c$ are fatigue ductility coefficient and fatigue ductility exponent respectively. $\Delta \varepsilon_{p}^{-}$is the plastic strain range from the cyclic equilibrium.The values of these constants are usually obtained through calibration of experimental data. The ductility exponent of metals ranges between -0.5 and $-0.7[29,30]$. The ductility coefficient for copper and aluminium range between 0.16 and 0.2 [29, 31]. These ranges give an upper and lower bounds of estimated life cycles. In this study, the maximum value of ductility coefficients for both materials is taken to be 0.2 . The upper and lower bound values of ductility exponent is taken as -0.5 and -0.7 to estimate upper and lower bounds for the number cycles to failure respectively

The whole simulation performed in this study was done on work station with Intel $(\mathrm{R}) \mathrm{Xeon}(\mathrm{R})$ 3.10GHz 2 processors, 128GB RAM, x64 Windows operating system.

\subsection{Results and Discussions for the lifetime comparison}

The temperature distribution in the power module for Case 1 and Case 2 at $\mathrm{t}=139 \mathrm{~s}$ (when power was on) is shown in Figure 6.

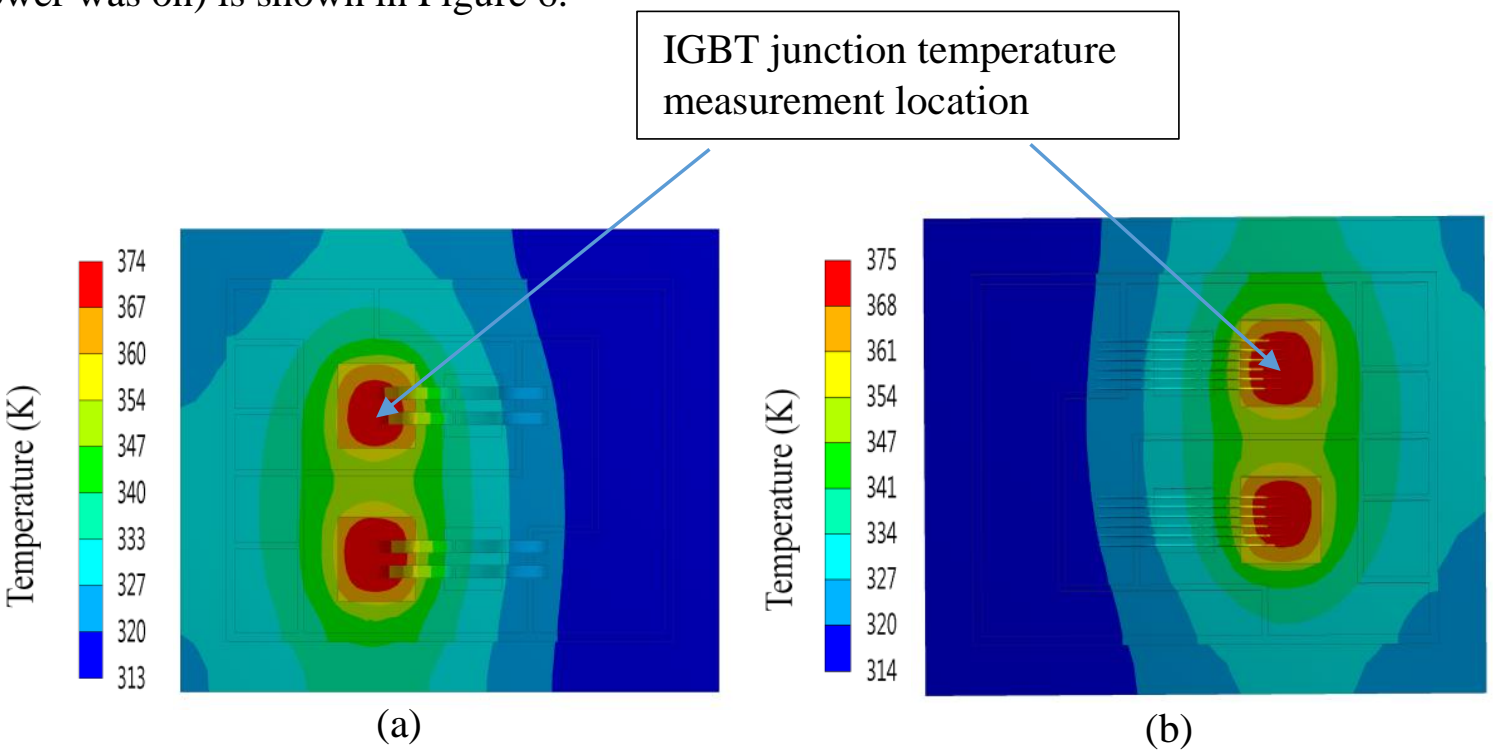

Figure 6. Temperature distribution in the power module for (a) Case 1 and (b) Case 2 at $t=139 \mathrm{~s}$ 
Figure 6 shows that the temperature distribution in the power modules are similar for the Case 1 and Case 2.This shows that similar temperature distribution in the power module will be achieved if three wire bonds of $400 \mu \mathrm{m}$ in diameter are replaced by a single ribbon of $2000 \mu \mathrm{m}$ x $200 \mu m$ cross-section under same current load. The maximum chip IGBT junction temperatures are very close which is $374 \mathrm{~K}$ for Case 1 and $375 \mathrm{~K}$ for Case 2 . The junction temperature describes the temperature inside the power device and must be within the specified range to ensure the reliability and safe operation of the power device. The maximum junction is within the recommended chip SOA which is $398 \mathrm{~K}$. Therefore failure other than wear out is prevented. The chip-wire/ribbon bond interface have same temperature which is essentially the value of the junction temperature.

The IGBT junction temperature history for Case 1 under power cycling is shown in Figure 7 while table 5 shows the values of the IGBT maximum and minimum junction temperature swing for all cases.

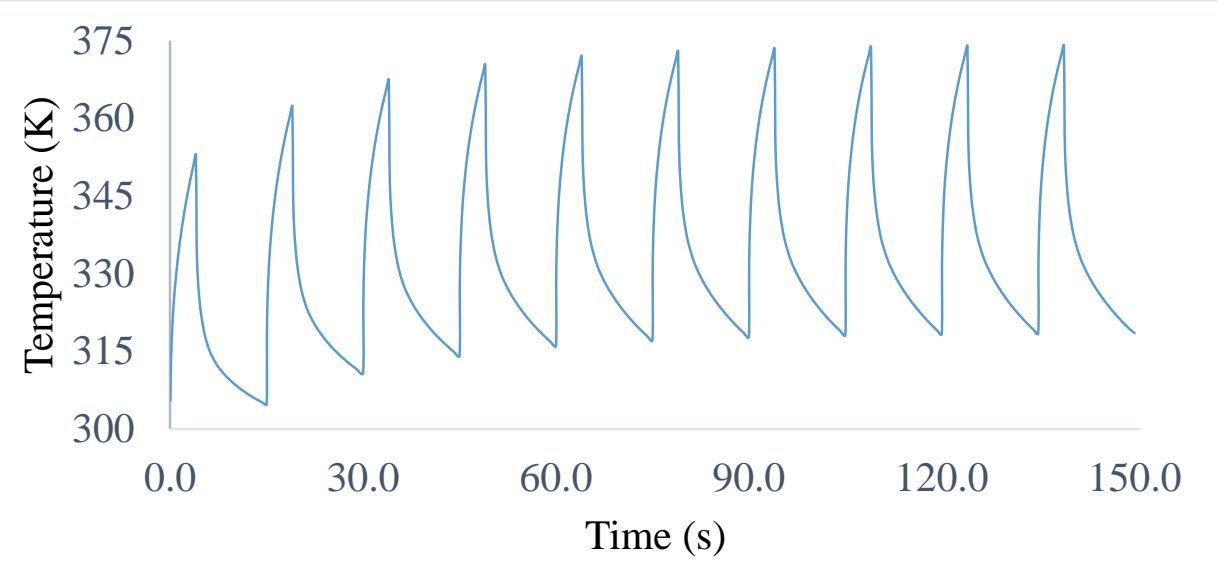

Figure 7. IGBT junction temperature history for case 1.

\begin{tabular}{|l|l|l|l|l|l|l|}
\hline & Case 1 & Case 2 & Case 3 & Case 4 & Case 5 & Case 6 \\
\hline $\mathrm{Tj}, \max (\mathrm{K})$ & 374 & 375 & 377 & 378 & 374 & 377 \\
\hline $\mathrm{Tj}, \min (\mathrm{K})$ & 317 & 318 & 319 & 320 & 318 & 319 \\
\hline
\end{tabular}

Table 5. IGBT junction temperature swing for all cases

The plot in Figure 7 shows that cyclic thermal equilibrium is achieved after four cycles. The maximum The results from Table 5 shows that under each design configuration and cases, the IGBT maximum junction temperature is close and within the recommended maximum junction temperature. This shows that the test conditions are within safe-operating area of the power devices and other failures besides wire/ribbon bonds and solder joints fatigue failure which could occur outside the SOA are prevented. The replacement of the wire bonds with ribbon bonds does not affect the junction temperature as well as replacing aluminium bond material to copper. Also, for this present simulation, the introduction of joule heating does not affect the junction temperature. 
The ribbon/wire bond volume weighted average temperature (VWAT) histories for the loading conditions are shown in Figure 8.

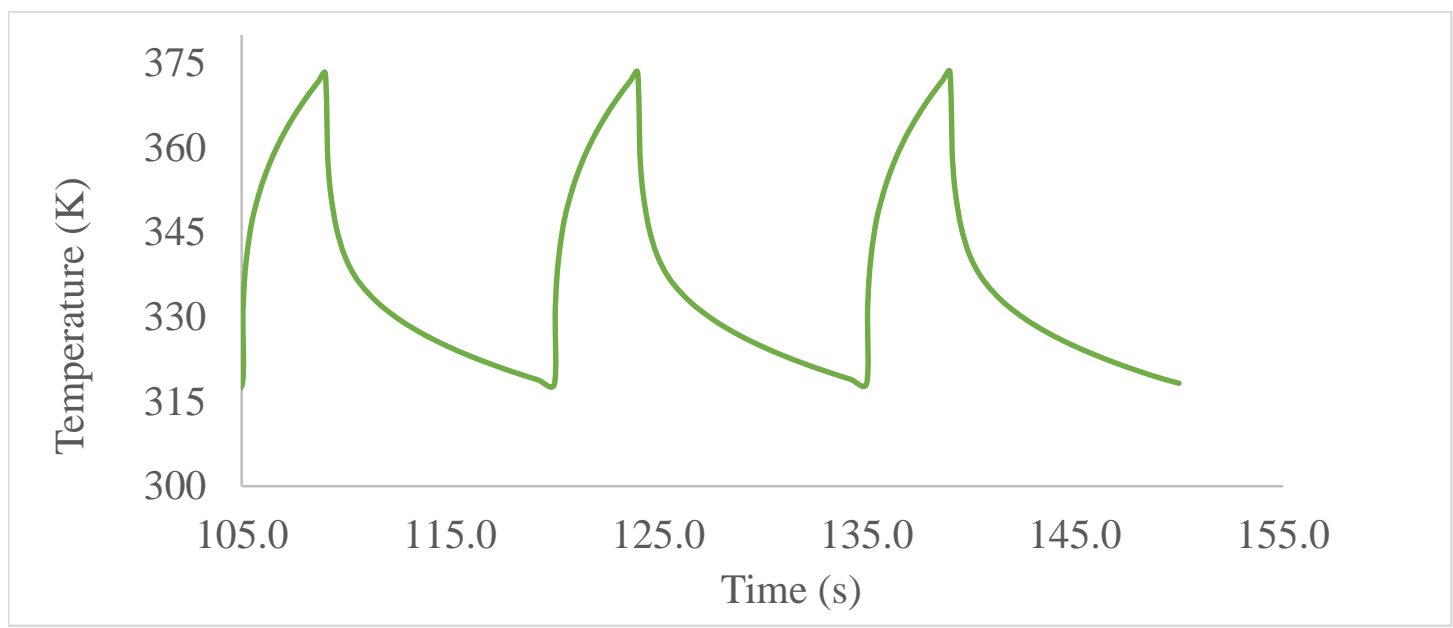

(a)

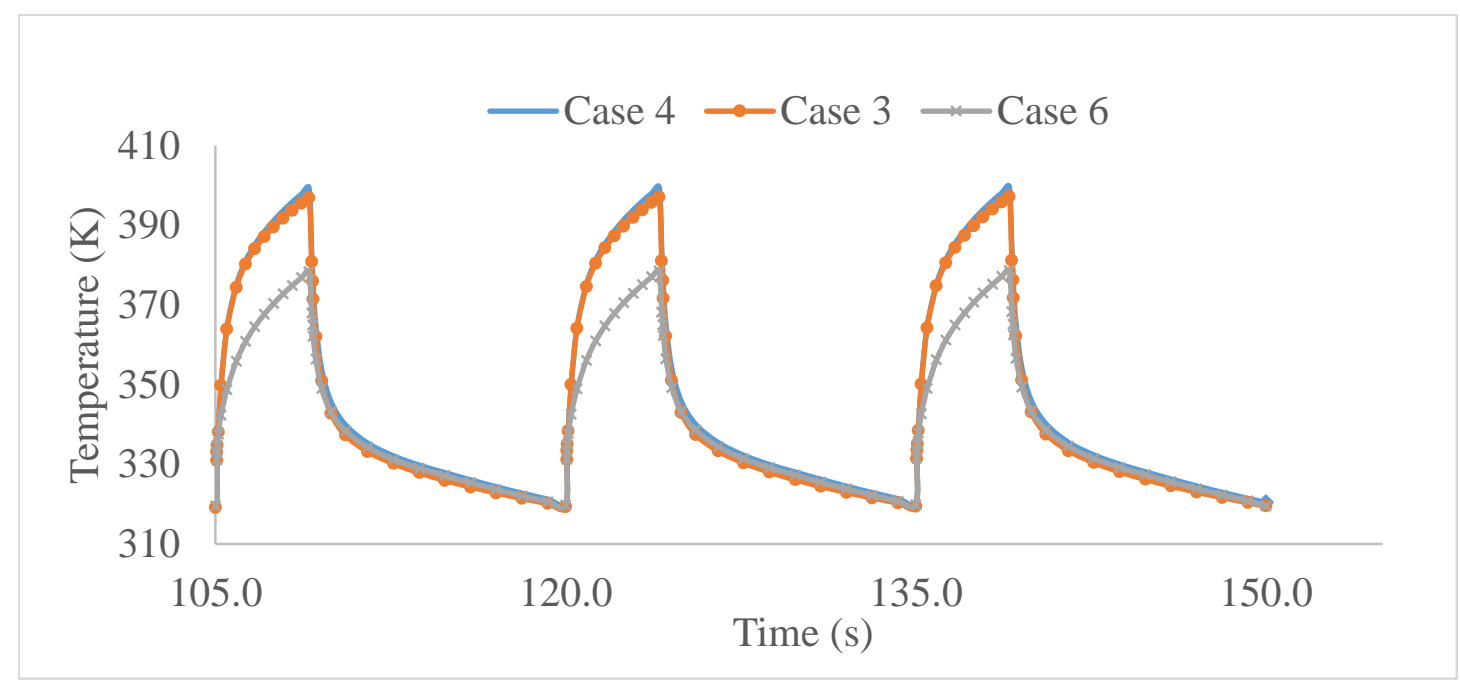

(b)

Figure 8. (a) VWAT history for Case 1. (b)VWAT histories for ribbon and wire temperature for second loading condition

Figure 8a shows the temperature history for the first loading condition for the Case 1 . The difference in the VWAT results for Case 1, Case 2 and Case 5 is very small and therefore, Case 2 and Case 5 are not shown. The VWAT is similar for the cases under the first loading condition because the temperatures in the wires and the ribbons for this loading condition are as a result of conduction only. Since, the heat from the IGBT chip is dissipated mostly downwards from the chip to the copper base plate, the temperatures in the wire and ribbon are expected to be relatively similar. The temperatures in the copper for Case 5 is slightly higher than Case 1 and Case 2 with only $2 \mathrm{~K}$. This is due to the higher thermal conductivity of copper. The Case 1 and Case 2 has identical temperature as expected because cross-sectional area equivalency is maintained in both cases and also both cases have the same material thermal conductivity which means that the thermal resistance values are similar in both cases. 
For the second loading condition where joule heating was considered, Figure $8 \mathrm{~b}$ shows that the VWAT for the copper ribbon (Case 6) is lower (maximum of $377 \mathrm{~K}$ ) than the ribbon bonds (Case 3 ) and the wire bonds (Case 4) with aluminium materials. This is due to the lower joule heating in the copper ribbon due its lower electrical resistivity (see Table 3 ). The inclusion of the joule heat obviously increases the average ribbon and wire bond temperatures for the two materials considered. The temperature in the ribbon for the Case 3 is slightly lower than the Case 4 for wire bond. The larger contact area between the ribbon bond and silicon provides a better heat dissipation contact resulting in lower temperatures in the ribbons than in the wires. The results show that the Case 1,2 and 5 all have similar temperature distribution for the first loading condition. For the second loading condition, the Case 6 has lower temperature compared to Case 3 and Case 4. Because of copper's superior thermal and electrical properties, this conclusion is expected and it shows that copper ribbon is also a good candidate for replacing wire bond.

Figure 9 shows the equivalent plastic strain $\left(\varepsilon_{p}^{e q v}\right)$ distribution in the ribbon (Case 1) and wire bond (Case 2$)$ at the end of the power cycling ( $\mathrm{t}=150 \mathrm{~s})$ while Table 6 gives the cyclic maximum and minimum $\varepsilon_{p}^{e q v}$ for all cases.
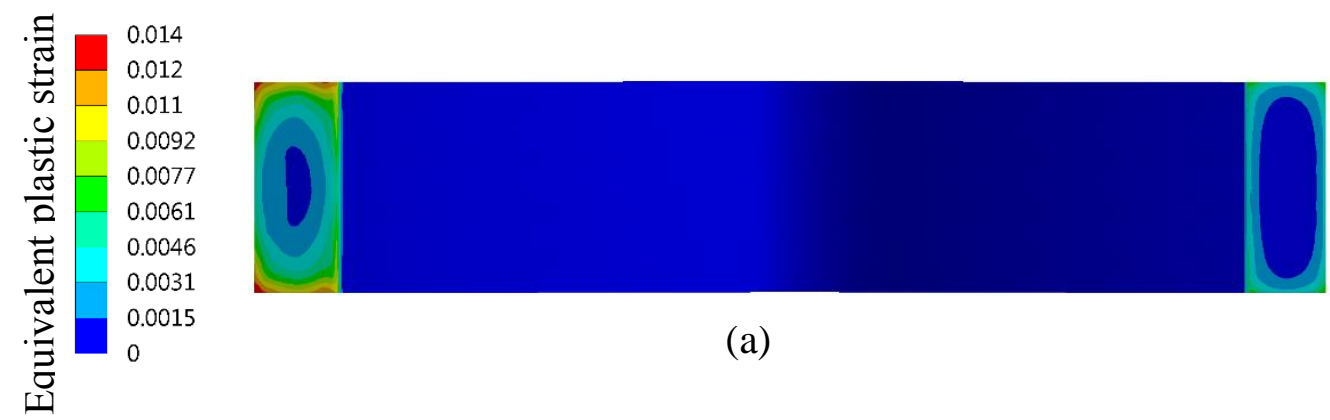

(a)

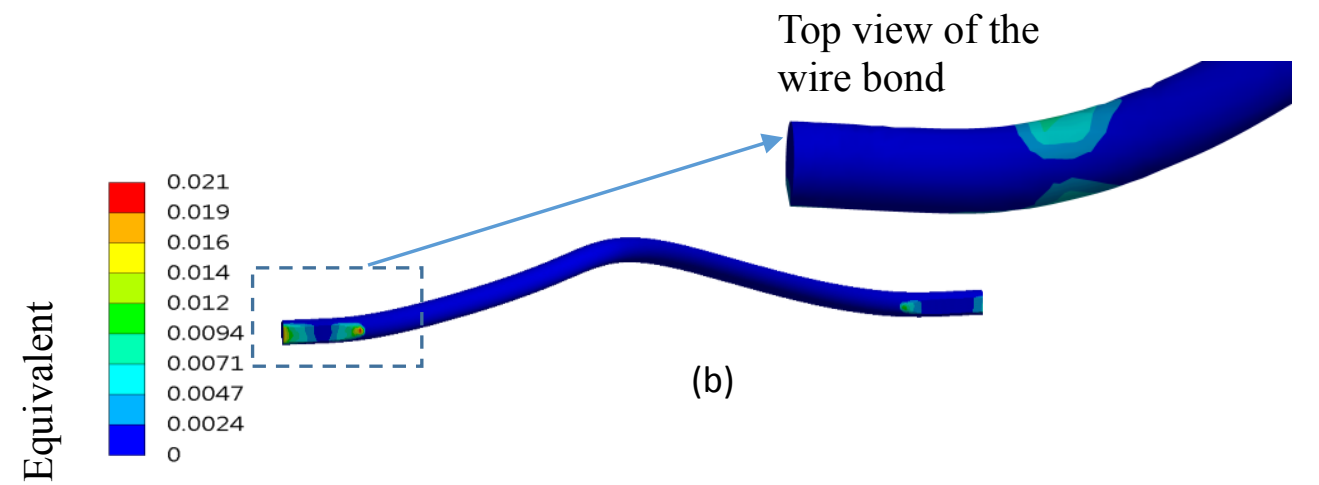

Figure 9. (a) $\varepsilon_{p}^{e q v}$ dist. in the ribbon (Case 1). (b) $\varepsilon_{p}^{e q v}$ dist. in the wire bond (Case 2). at t=150s.

\begin{tabular}{|c|c|c|c|c|c|c|}
\hline $\begin{array}{c}\text { Equivalent } \\
\text { plastic } \\
\text { strain }\end{array}$ & Case 1 & Case 2 & Case 3 & Case 4 & Case 5 & Case 6 \\
\hline Max (\%) & 2.01 & 2.75 & 2.42 & 3.20 & 0.67 & 0.72 \\
\hline Min (\%) & 1.40 & 2.10 & 1.78 & 2.51 & 0.58 & 0.62 \\
\hline
\end{tabular}

Table 6 . The cyclic maximum and minimum equivalent plastic strain for all cases. 
Figure 9 shows that the $\varepsilon_{p}^{e q v}$ distribution is concentric in the ribbon bond and the maximum values are located at the corners where cracks are expected to appear. When cracked areas expand, bond lift may happen. For wire bonds, the $\varepsilon_{p}^{e q v}$ is maximum at the bond interface and concentrated also at the bond heel. This shows a bond wire lift off dominant failure mode and also a potential heel crack failure due to wire flexure.

The plastic strain is higher at the IGBT-wire/ribbon interface than at the diode-wire/ribbon interface as expected. This is obviously due to the higher temperature at the IGBT-wire/ribbon interface. The results have indicated a less flexure in the ribbon bond than in the wire bond. This less flexing of the ribbon bond can also be attributed to its larger surface area and large bond contact area which reduces ribbon displacement (deformation) or ability to absorb large deformations and stresses during the thermal expansion and contraction [1].

Table 6 shows that the $\varepsilon_{p}^{e q v}$ is always higher in the wire bond than in the ribbon for both loading conditions. This could be the result of the ribbon bond having less flexure which results in lower stress/strain at the bond interface compared to wire bond. Also, the large bond area for the ribbon bond can be attributed with less strain for the ribbon due a possibly reduced local CTE mismatch. The inclusion of joule heating in the simulation, increases the plastic strain when compared with cases without joule heating. This is expected as the increased temperature will increase stress and strain. Copper has lower plastic strain obviously due to its higher yield strength. The results in Table 6 could be used for design optimization and predicting the power module lifetime as have been performed below.

Using the cyclic equivalent plastic strain range from the results in Table 6 and the expression in (10), the number of cycles to failure for the upper and lower bounds are computed and shown in Table 7.

\begin{tabular}{|l|l|l|l|l|l|l|}
\hline \multicolumn{1}{|c|}{$N_{f}$} & Case 1 & Case 2 & Case 3 & Case 4 & Case 5 & Case 6 \\
\hline $\begin{array}{l}\text { Upper } \\
\text { bound }\end{array}$ & 2150 & 1893 & 1953 & 1680 & 98765 & 80000 \\
\hline $\begin{array}{l}\text { Lower } \\
\text { bound }\end{array}$ & 197 & 180 & 184 & 165 & 3031 & 2607 \\
\hline
\end{tabular}

Table 7: Computed number of cycles to failure for each case

From Table 7, it is seen that the ribbon bond has higher fatigue life than the wire bond as expected due to lower strain in the ribbon bonds observed. The introduction of joule heat reduces the estimated life-time because of the increased temperature. For example, there is about $6.6 \%$ to $9.2 \%$ reduction in the computed fatigue life for the wire bond when joule heating is introduced in the simulation. Almost $10 \%$ different in estimated fatigue life is quite interesting and cannot not be neglected. Therefore, it would be better to consider joule heating in the wires/ribbons during power cycling simulation. The copper fatigue life is more than four order of magnitude higher than aluminium as expected. This is due to the high value of the copper yield strength used in the simulation (see Table 3). This shows that the copper reliability is very high when compared with $\mathrm{Al}$ ribbon bonds. Of course, this does not take in account other factors such as copper cost and formation of weak intermetallic compound IMC. 


\section{Parametric study of the ribbon bond under power and thermal cycling conditions}

Parametric analysis and Design of Experiments DoE method have been used in the analyses performed in this section using FEA. The parametric study was used to understand how ribbon loop height and ribbon thickness affect temperature and equivalent plastic strain in the ribbon bond under thermal and power cycling. This essentially answers the "what if" question. The design points for the parametric analysis were not selected with any algorithm but by keeping one design variable constant at a time and varying the other variable. On the other hand, the DoE uses algorithm in predicting design points needed to perform power cycling using FEA. DoE method ensures that the predicted design points are evenly distributed in given design space. The results obtained from the DoE can be used in developing a robust response surface RS approximation model using least squares fitting/regression techniques. The resulting RS model is very useful especially when optimization analysis is required, understanding influence and interaction of design variables or for predicting response for other design points not contained in the experimental design. Figure 10 is a typical ribbon bond in 2D representation showing the bond loop height $\mathrm{h}(\mathrm{mm})$ and ribbon thickness $\mathrm{t}(\mathrm{mm})$.

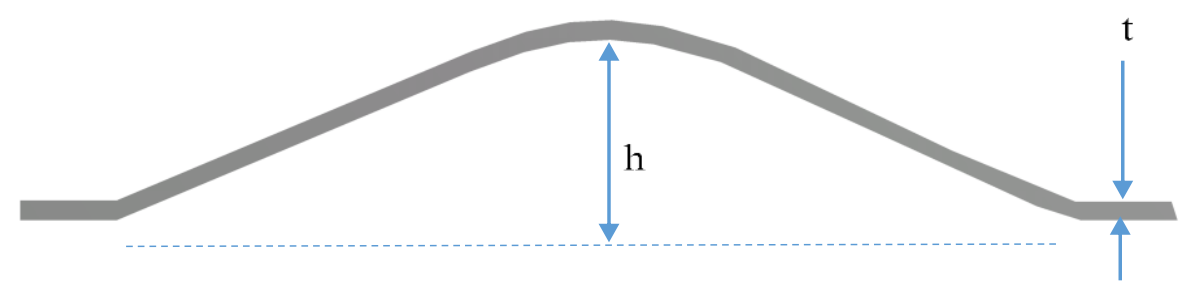

Figure 10. Ribbon bond representation in 2D showing the bond loop height and ribbon thickness

In both parametric and DoE analysis, the design space for the ribbon bond for the thermal and power cycling is given in the Table 8 . The aluminium ribbon bond span is $13.75 \mathrm{~mm}$ and is kept constant.

\begin{tabular}{|l|l|l|}
\cline { 2 - 3 } \multicolumn{1}{c|}{} & Thickness $(\mathrm{mm})$ & Loop-Height $(\mathrm{mm})$ \\
\hline Lower bound & 0.1 & 1.5 \\
\hline Upper bound & 0.3 & 3.5 \\
\hline
\end{tabular}

Table 8. Design space for the ribbon bond for power cycling and thermal cycling

In the parametric study, for every ribbon thickness, the loop height was changed from $1.5 \mathrm{~mm}$ to $3.5 \mathrm{~mm}$ with $0.5 \mathrm{~mm}$ increment. This results in 15 FEA simulations for the power cycling and thermal cycling each.

Two cases were studied in the parametric analysis. Case 1 requires maintaining a constant cross-sectional area to be $0.4 \mathrm{~mm}^{2}$ in order to ensure current carrying capability equivalent. This requires varying the width value for each thickness to achieve this. In Case 2, width value was kept constant at $2 \mathrm{~mm}$ while the thickness was varied. So in Case 2, cross-sectional area varied from $0.2 \mathrm{~mm}^{2}$ to $0.6 \mathrm{~mm}^{2}$. In each case, the loop height was also varied from $1.5 \mathrm{~mm}$ to $3.5 \mathrm{~mm}$. 
For the DoE, the Latin Hypercube Sampling (LHS) was used to determine sampling points. The ribbon width was kept constant at $2 \mathrm{~mm}$. The LHS method [32] is a widely used sampling method to generate controlled random samples with equal probability. It uses the number of specified sampling points to determine the number of experimental points. There are other DoE methods such as central composite design, three-level orthogonal arrays, and two or three level factorial design [33]. The Latin Hypercube is often preferred over other sampling methods because it provides experimental points throughout the design space while many other methods only use points at the boundary of n-dimensional hypercube of the design space [33].

To reduce computational costs and time, FEA for each design point under power cycling is performed using a sub-modelling technique described in section 3.1. The same loading and boundary conditions described in section 3.1 is also used for the power cycling analysis using ANSYS parametric design environment. The results obtained from the DoE are used to generate the RS model and perform sensitivity analysis using VisualDoc v.6.0 [34].

The average simulation run time (minutes) for each design point for the power cycling simulation for the two cases in parametric study and DoE is given Table 9. It should also be noted that similar simulation run times stated in the Table 9 were obtained for the six cases presented section 4.0.

\begin{tabular}{|l|c|}
\hline Simulation & Time (minutes) \\
\hline Thermal analysis & 8 \\
\hline Coarse thermo-mechanical & 40 \\
\hline Sub-model & 125 \\
\hline
\end{tabular}

Table 9. Average simulation run time for each design point for the power cycling analysis

For the thermal cycling, only a parametric analysis was performed. A simplified 2D plane strain representation of the model shown in Figure 11 and design space in Table 8 were used. Temperature range is between $233 \mathrm{~K}$ to $393 \mathrm{~K}$ with a ramp time of 4 minutes and dwell time of 6 minutes. Four thermal cycles were simulated with an average simulation run time for each design point being 15 minutes.

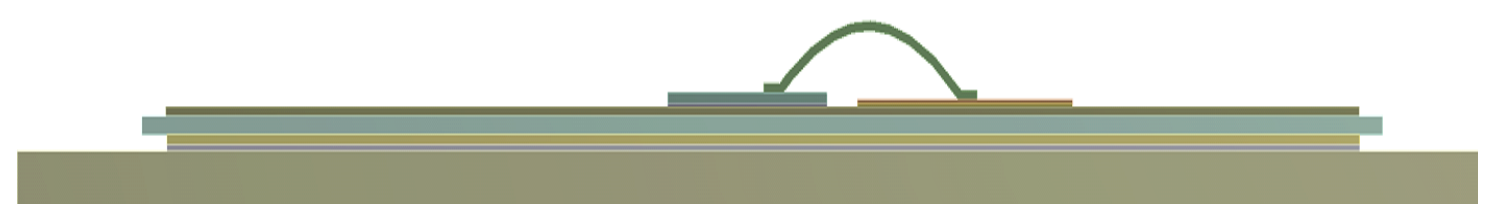

Figure 11. 2D representation of the model 


\subsection{Temperature responses under power cycling for constant cross-sectional area}

The maximum ribbon bond VWAT and the maximum IGBT junction temperature results for different loop heights under constant thickness is shown in the Figure 12 for the Case 1.

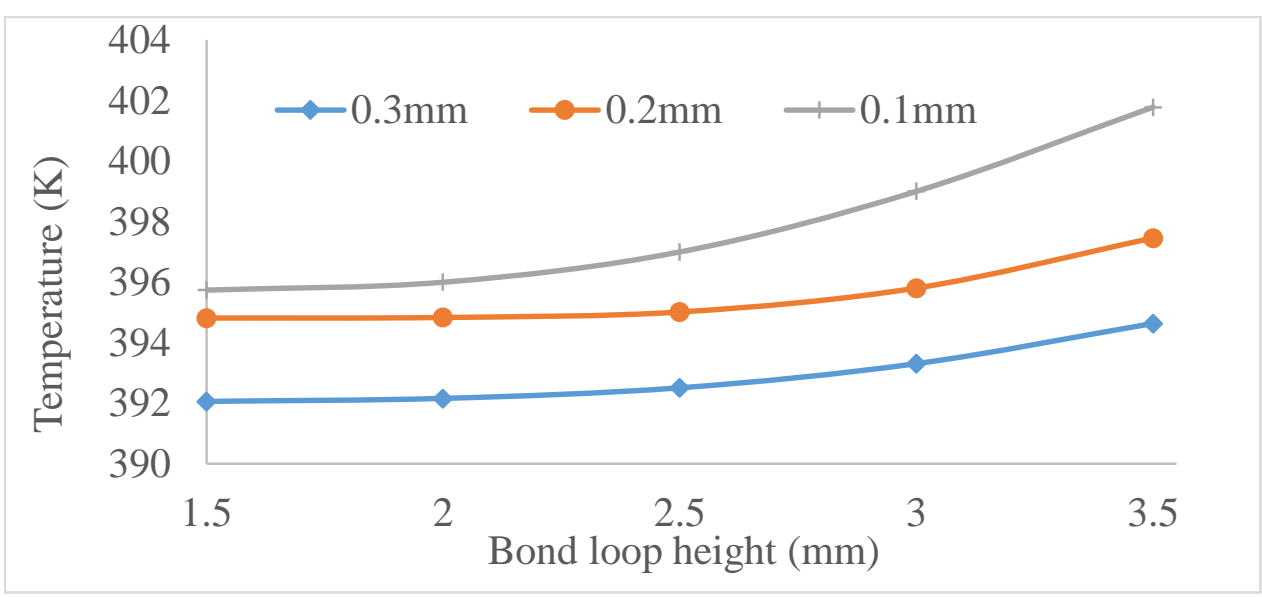

(a)

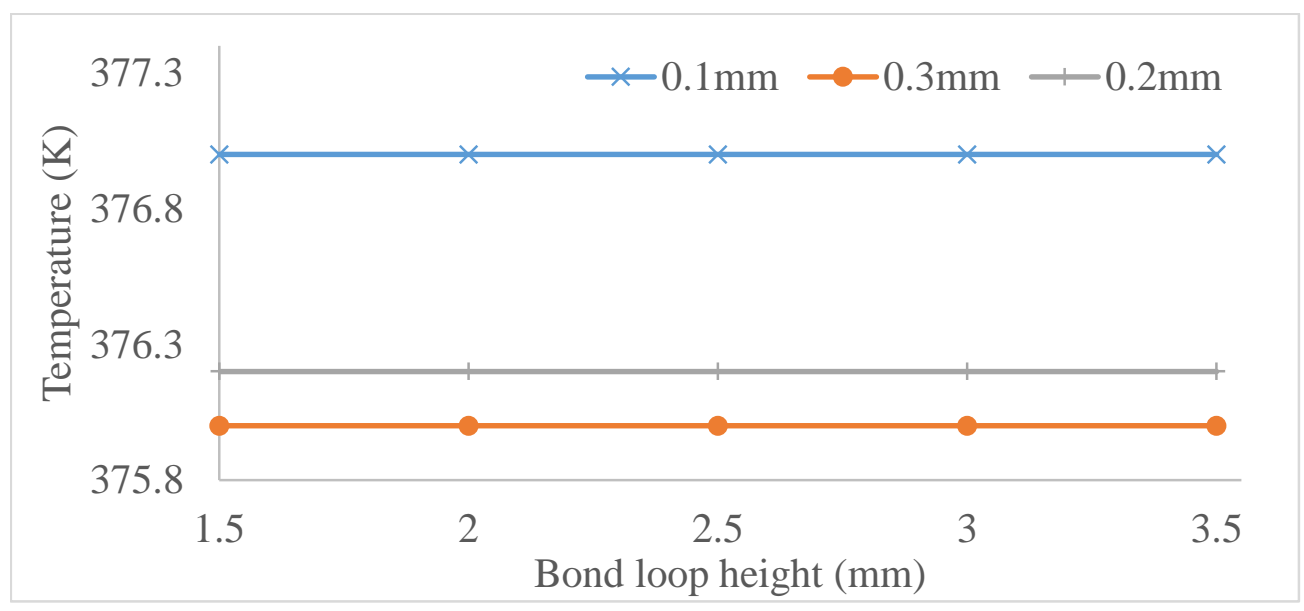

(b)

Figure 12. (a) Maximum ribbon bond VWAT for different loop heights under constant thickness for the Case 1. (b) Maximum IGBT junction temperature for different loop heights under constant thickness for the Case 1.

Figure 12a shows that there is a slight increase in the temperature when loop height is increased under a constant thickness. The overall change in the maximum ribbon bond VWAT under any thickness and loop height combination is less than $10 \mathrm{~K}$. For example, the maximum ribbon bond VWAT increased from $396 \mathrm{~K}$ to $402 \mathrm{~K}$ when the loop height increased from $1.5 \mathrm{~mm}$ to $3.5 \mathrm{~mm}$ under $0.1 \mathrm{~mm}$ constant thickness. It also increases slightly when thickness is reduced under a constant loop height as a result of reduced thermal resistance. Figure $12 \mathrm{~b}$ shows that maximum IGBT junction temperature remains constant regardless of change in loop height. Only change in thickness under constant loop height that slightly changed the IGBT maximum junction temperature. For example, from $0.3 \mathrm{~mm}$ to $0.1 \mathrm{~mm}$ change in thickness under $3.5 \mathrm{~mm}$ loop height, the Maximum IGBT junction temperature increased only by $1 \mathrm{~K}$, which is negligible. It can then be concluded that the maximum IGBT junction temperature is not 
significantly affected by the ribbon thickness in this case. These results have shown that if the cross-sectional area is maintained, changes in thickness or loop height does not affect the average temperature in the ribbon significantly nor the maximum IGBT junction temperature.

\subsection{Temperature responses under power cycling for constant width}

The maximum ribbon bond VWAT and maximum IGBT junction temperature results for different loop heights under constant thicknesses is shown in the Figure 13 for the Case 2.

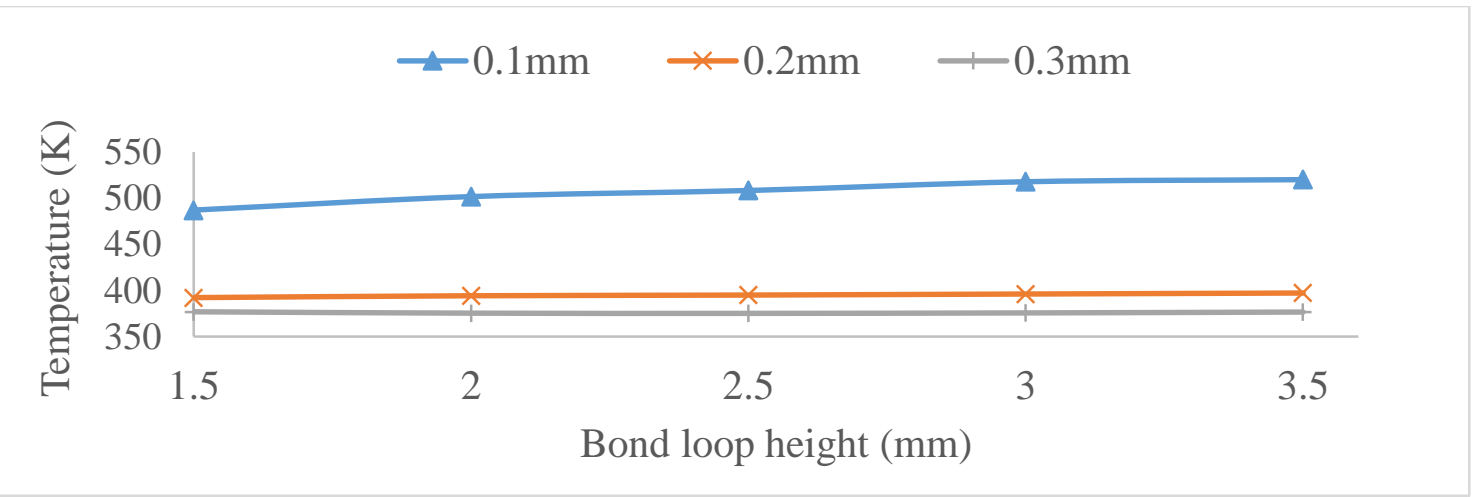

(a)

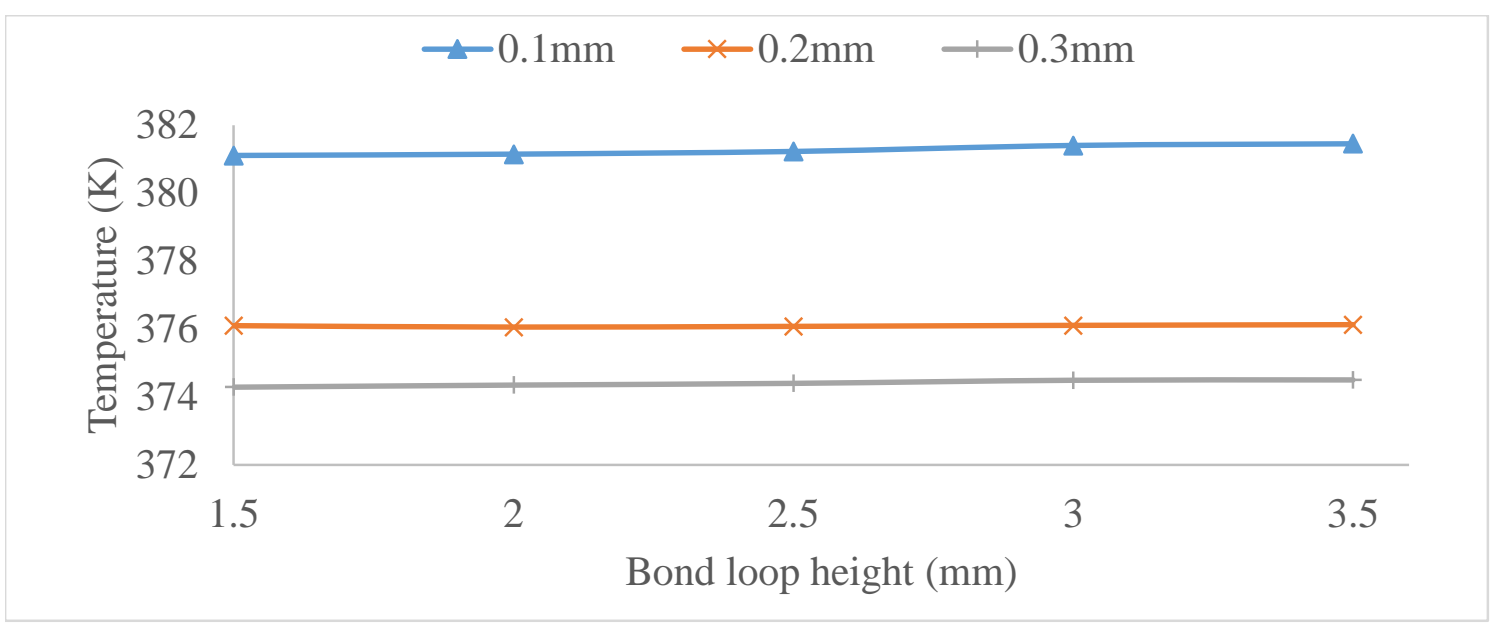

(b)

Figure 13. (a) Maximum ribbon bond VWAT for different loop heights under constant thickness for the Case 2. (b) Maximum IGBT junction temperature for different loop heights under constant thickness for the Case 2.

The results from Figure 13a showed that under a constant ribbon bond thickness and $2 \mathrm{~mm}$ width, increasing the loop height increases the ribbon temperature slightly (almost similar). However, reducing the thickness of ribbon bond increases the ribbon temperature quite significantly. This is obviously as a result of increase in heat generation due to volume reduction as well as decreased thermal resistance due to a reduced thickness. The increase in temperature from a decrease in the ribbon thickness from $0.3 \mathrm{~mm}$ to $0.1 \mathrm{~mm}$ is more than $100 \mathrm{~K}$.Ofcourse, there is no surprise in this result because since cross-sectional area equivalency is no longer maintained for the same current loading, increased heat generation and reduced 
thermal resistance for the small thickness will increase the ribbon bond overall temperature. However, surprisingly, such increase in the ribbon bond temperature due reduction in thickness increased the maximum IGBT junction temperature by only $8 \mathrm{~K}$ (see Figure 13b). This is however as a result of efficient and effective conduction capability of other layers in the structure and the forced cooling system used, providing an excellent heat dissipation path. Also Figure 13b showed that loop height change has no effect on the maximum IGBT junction temperature under a constant thickness even when cross-sectional area equivalency is not maintained.

It can be concluded from the two cases above, that both loop height increase and reduction in the ribbon bond thickness increases the ribbon bond temperatures. How much increase in temperature depends on whether the cross-sectional area is constant for the same current load. Also, the possibility of increasing the IGBT junction temperature beyond its SOA is high if a very small ribbon bond thickness is used without efficient cooling system.

\subsection{Equivalent plastic strain results from the parametric study}

The maximum $\varepsilon_{p}^{e q v}$ at the ribbon bond interface at $\mathrm{t}=150$ s (end of cycling) for different loop heights under different constant ribbon thicknesses for the Case 1 and the Case 2 are shown in the Figure 14. The maximum $\varepsilon_{p}^{e q v}$ at the ribbon bond interface from thermal cycling is shown in the Figures 15.

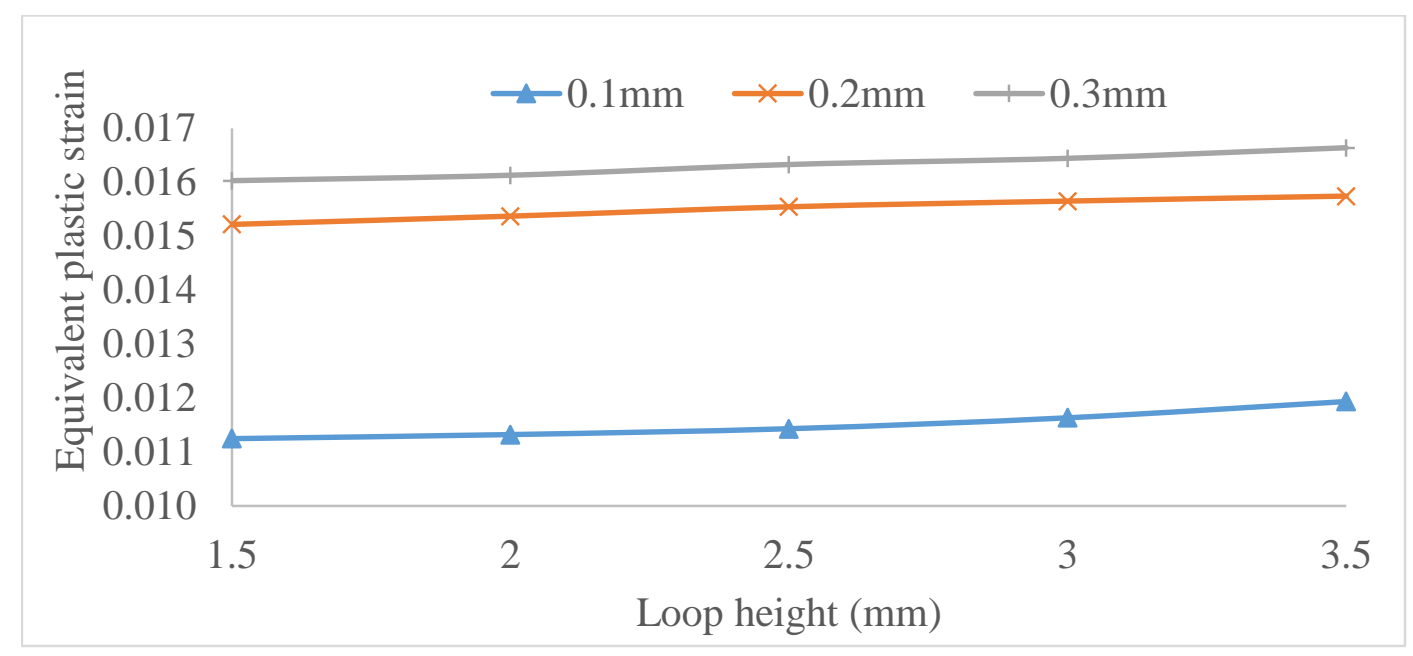

(a) 


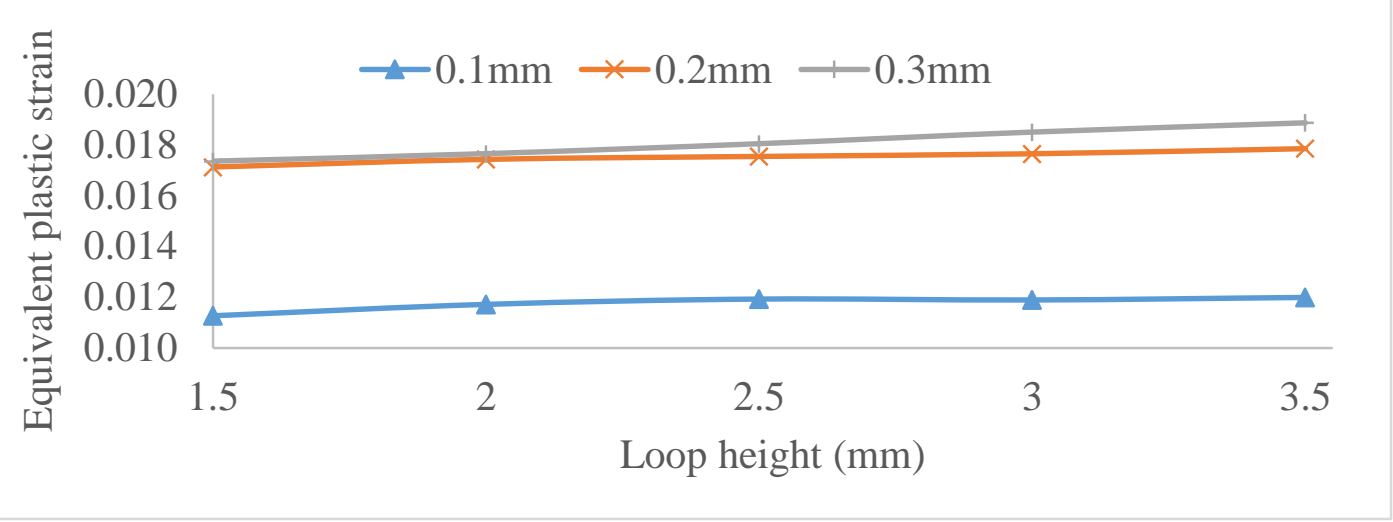

(b)

Figure 14. (a) Maximum $\varepsilon_{p}^{e q v}$ at the bond interface at $\mathrm{t}=150$ s for different loop heights under different constant thicknesses from power cycling for the Case 1. (b) Maximum $\varepsilon_{p}^{e q v}$ at the bond interface at $\mathrm{t}=150 \mathrm{~s}$ for different loop heights under different constant thicknesses from power cycling for the Case 2.

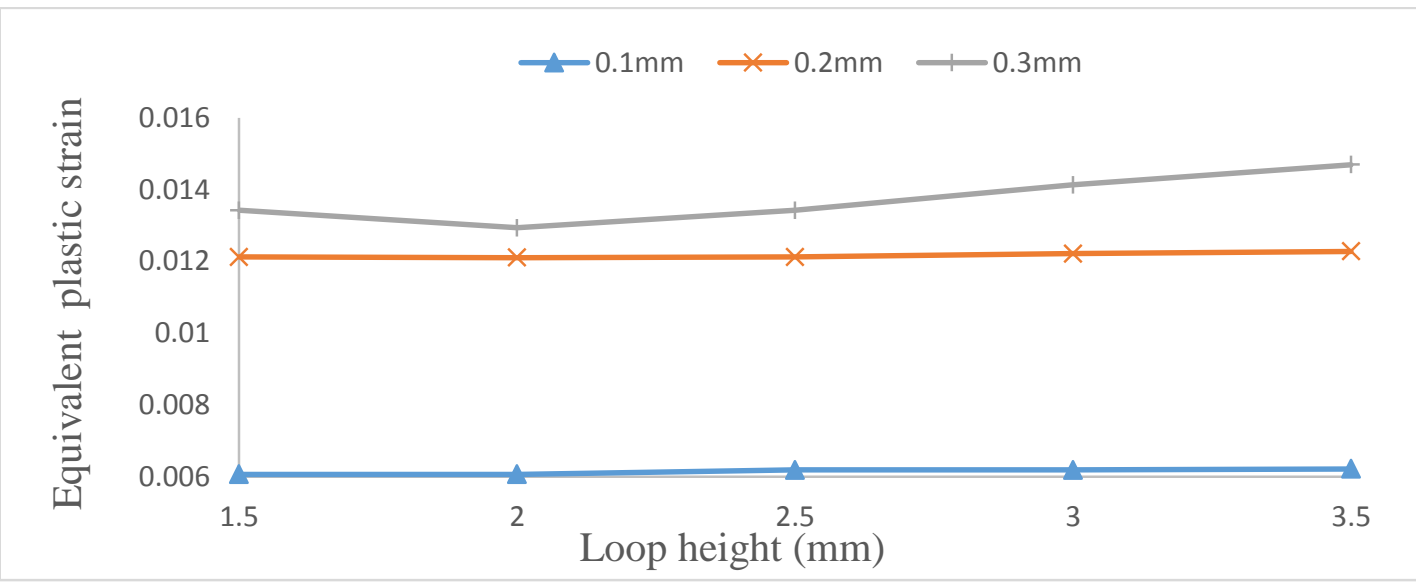

Figure 15. Maximum $\varepsilon_{p}^{e q v}$ at the bond interface for different loop heights under different constant thickness from thermal cycling

The results from Figures 14a, 14b and 15 showed that under a constant ribbon bond thickness, the $\varepsilon_{p}^{e q v}$ increases slightly (almost similar) as loop height increases for both thermal and power cycling. The $\varepsilon_{p}^{e q v}$ at the bond interface increases significantly as the ribbon bond thickness increases for a given loop height. This shows that ribbon bond thickness has more influence on the equivalent plastic strain than the bond loop height. Maintaining a constant cross-sectional area did not produce relatively close values for the stress and strain in the ribbon bond as was the case for temperature. However, lower strain is recorded in the Case 1 than in Case 2 for any thickness and loop height combination. This can be attributed to the reduced temperature in the Case 1. 
The reduced stress/strain for the lower ribbon bond thickness can also be attributed to the higher flexural compliance of the smaller ribbon bond thickness than a thicker ribbon bond, also similar to observation by Meyyappan [10] under thermal cycling with wire bonds.

\subsection{Response Surface Model and Sensitivity Analysis}

The ribbon bond maximum VWAT at $\mathrm{t}=139 \mathrm{~s}$ and the maximum $\varepsilon_{p}^{e q v}$ at the bond interface at the end of the cycling $(t=150 \mathrm{~s})$ is given in the Table 10 (column 4 and 5 respectively) for each LHS design point. The first column in Table 10 is the design point number, second and third columns are the values of the LHS design variables for each design point number.

\begin{tabular}{|c|c|c|c|c|}
\hline $\begin{array}{c}\text { LHS design } \\
\text { point number }\end{array}$ & Thickness $(\mathrm{mm})$ & Loop height $(\mathrm{mm})$ & Temperature (K) & $\begin{array}{c}\text { Equivalent } \\
\text { plastic strain }\end{array}$ \\
\hline 1 & 0.25 & 2.63 & 383 & 0.0182 \\
\hline 2 & 0.20 & 3.03 & 397 & 0.0173 \\
\hline 3 & 0.21 & 1.57 & 388 & 0.0169 \\
\hline 4 & 0.11 & 2.90 & 490 & 0.00876 \\
\hline 5 & 0.13 & 1.70 & 434 & 0.0107 \\
\hline 6 & 0.12 & 3.43 & 466 & 0.0099 \\
\hline 7 & 0.28 & 2.77 & 379 & 0.0175 \\
\hline 8 & 0.24 & 3.30 & 387 & 0.0164 \\
\hline 9 & 0.15 & 2.10 & 424 & 0.0115 \\
\hline 10 & 0.23 & 1.97 & 388 & 0.0148 \\
\hline 11 & 0.17 & 2.37 & 406 & 0.012 \\
\hline 12 & 0.27 & 1.83 & 379 & 0.0179 \\
\hline 13 & 0.19 & 2.50 & 401 & 0.0154 \\
\hline 14 & 0.29 & 3.17 & 377 & 0.0191 \\
\hline 15 & 0.16 & 2.23 & 415 & 0.0117 \\
\hline
\end{tabular}

Table 10. The ribbon bond maximum VWAT $(\mathrm{t}=139 \mathrm{~s})$ and the maximum $\varepsilon_{p}^{e q v}(\mathrm{t}=150 \mathrm{~s})$ results for each Latin Hypercube design point.

Examining the results in the Table 10 shows that DoE alone can also be used to analyse the influence of changing the design variables. However, more time is required to see the occurrences or a complex plot of the design variables and their responses are required.

Polynomial approximation (i.e. response surface RS model or curve fit) of the responses is constructed using results in Table 10. The construction of the RS model is performed using VisualDoc. The responses are the temperature (the ribbon bond maximum VWAT) and maximum $\varepsilon_{p}^{e q v}$ at the bond interface. The variables are the ribbon bond thickness and the bond loop height. The resulting RS model is a function of the design variables. The RS model can be constructed using various regression model methods such as forward, backward elimination and stepwise regression method [34]. The forward stepwise regression method eliminates terms with less significance in the RS model [34] and is used in this study. The forward regression method begins without any candidate variable in the model and initially selecting the variable with the highest R-squared (coefficient of determination) value. Subsequently at each step, the 
candidate variable that increases the R-squared is selected. Adding of variables is stopped when the remaining variables add no significance.

To evaluate the predictive capability and accuracy of the constructed RS models (i.e. how well they can predict the responses given the design variables), analysis of residuals and residual plots are often used. The residual is an error measure of the RS model. However, unscaled residual often do not convey some vital information. Such as indicating which design points not adequately captured by the RS model. The standardised scaled residual $\left(d_{i}\right)$ is better in this regard [34] and has been used in this study. $d_{i}$ is the standardised scaled residual for ith design point.

The standardised scaled residual $\left(d_{i}\right)$ is computed using the expressions in (11).

$$
\begin{gathered}
d_{i}=\frac{e_{i}}{\sqrt{M S E}} \quad i=1, \ldots, N \\
e_{i}=\left(\mathrm{x}_{a i}-\mathrm{x}_{b i}\right) \\
M S E=\frac{S S_{E}}{N-p} \\
S S_{E}=\sum_{i}^{N} e_{i}{ }^{2}
\end{gathered}
$$

Where $e_{i}$ is the residual at a design point $i . \mathrm{x}_{a i}$ is the actual response for the $i$ th design point (such as the values from FEA simulation, i.e. values in the $4^{\text {th }}$ and $5^{\text {th }}$ column in Table 10). $\mathrm{x}_{b i}$ is the predicted response for the ith design point using the RS model, MSE is the mean squared error, $S S_{E}$ is the squared sum of errors, $N$ is number of design points which is 15 in this study, $p$ is the number of terms in the RS model. A measure of good predictive capability of the RS model is when most of the standardised scaled residuals lie in the interval [-3 $\leq$ $\left.d_{i} \leq 3\right][34]$.

The construction of the RS model and computation of the standardised scaled residual is performed using the results from the DoE analysis (Table 10) making use of the commercial software VisuaDoc. The design points' variables and their responses computed from FEA are inputs that VisualDoc required to construct the RS model and the standardised scaled residuals using the methods and expressions presented above. The construction of the RS model and standardised scaled residual for this study is less than one minute (10 seconds precisely). This excludes the time to input the design points and their responses as well as general settings.

The RS model obtained from the stepwise regression method for the temperature (the maximum ribbon bond VWAT) and equivalent plastic strain (maximum $\varepsilon_{p}^{e q v}$ at the bond interface ) as functions of the design variables (ribbon bond thickness $\mathrm{t}(\mathrm{mm}$ ) and bond loop height $\mathrm{h}(\mathrm{mm})$ ) using VisualDoc software are given in (12) and (13) respectively.

$$
\begin{array}{r}
\mathrm{T}([\mathrm{h}(\mathrm{mm})],[\mathrm{t}(\mathrm{mm})])=579.52-1768.31 \mathrm{t}+27.7 \mathrm{~h}-114.01 \mathrm{ht}+3916.34 \mathrm{t}^{2} \\
\varepsilon_{\mathrm{p}}([\mathrm{h}(\mathrm{mm})],[\mathrm{t}(\mathrm{mm})])=-0.00307+0.128 \mathrm{t}-0.186 \mathrm{t}^{2}+0.0001 \mathrm{~h}
\end{array}
$$


where $\mathrm{t}$ and $\mathrm{h}$ are the ribbon thickness and bond loop height in millimetres.

Using (12) and (13), the maximum volume averaged temperature in a ribbon bond and maximum equivalent plastic strain at ribbon bond interface in terms of ribbon thickness and bond loop height can be approximated without performing FEA simulation.

The standardised scaled residual plot for temperature using RS model (12) and equivalent plastic strain using RS model (13) for the 15 design points $\mathrm{Di}(\mathrm{i}=1-15)$ is shown in the Figure 16.

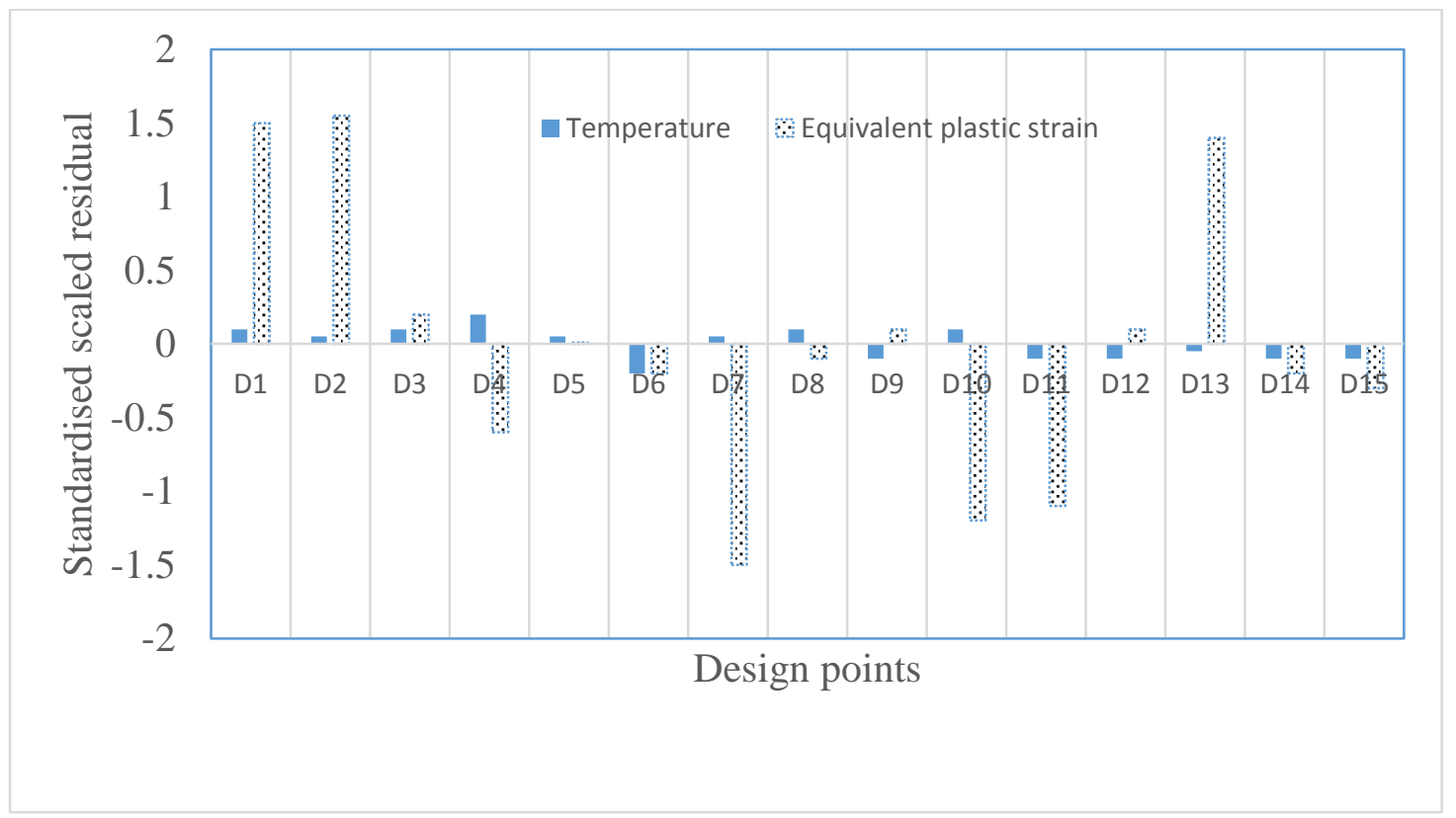

Figure 16. Standardised scaled residuals for the design points using RS models

As can be seen in the Figure 16, the standardised scaled residual for the RS model for temperature (12) is very small between -0.05 to 0.1 while that for equivalent plastic strain (13) ranges from -1.55 to 1.55 . This shows that the RS model for temperature has more accurate predictive capability for all design points than the RS model for equivalent plastic strain.

Overall, the standardised scaled residual $d_{i}$ for all the design points lies between -1.55 and 1.55 which is within the recommended interval of $\left[-3 \leq d_{i} \leq 3\right]$ [34]. The Figure 16 showed that RS models (12) for temperature and (13) for equivalent plastic strain have good predictive capabilities. Therefore, they can be used to predict responses of other design points without performing FEA simulation and also can be used for design optimization analysis.

Sensitivity analysis is used to determine the importance and level of influence of design variables and their interactions in the RS model. The sensitivities are obtained from the coefficients in the RS approximation model such as (12) and (13). However, often design variables are in different unit scales making direct sensitivity comparison difficult. To 
overcome such problem, normalisation of the design variables are performed [34]. Then using the normalised variables and the same fitting techniques as previous, a new RS model is constructed. The normalisation of design variables is performed using (14) such that design variables values are between -1 and 1 .

$$
D V_{s C}=\frac{D V_{u n s c^{-}}\left(\max \left[D V_{u n s c}\right]+\min \left[D V_{u n s c}\right]\right) / 2}{\left(\max \left[D V_{u n s c}\right]-\min \left[D V_{u n s c}\right]\right) / 2}
$$

where $D V_{s c}$ is the normalised design variable, $D V_{u n s c}$ is the un-normalised design variable, $\max \left[D V_{u n s c}\right]$ is the maximum un-normalised design variable and $\min \left[D V_{u n s c}\right]$ is the minimum un-normalised design variable. For example, in this study, the maximum unnormalised loop height and thickness values are $3.5 \mathrm{~mm}$ and $0.3 \mathrm{~mm}$ respectively. The minimum un-normalised loop height and thickness values are $1.5 \mathrm{~mm}$ and $0.1 \mathrm{~mm}$ respectively. Therefore, the normalised values of the upper and lower bounds used in this study is -1 for $0.1 \mathrm{~mm}$ un-normalised thickness, -1 for $1.5 \mathrm{~mm}$ loop height, 1 for $0.3 \mathrm{~mm}$ thickness and 1 for $3.5 \mathrm{~mm}$ loop height. Using this scaling method for the LHS design points (see Table 10), it can be seen that one scaled unit of change in the normalised design space for both ribbon bond thickness and ribbon loop height corresponds to changes of $0.11 \mathrm{~mm}$ and $0.93 \mathrm{~mm}$ in their values respectively.

Using these normalised variables from the LHS design points and their corresponding responses, the new RS model is constructed using VisualDoc and given in (15) for temperature and (16) for equivalent plastic strain.

$$
\begin{aligned}
& \mathrm{T}([\mathrm{h}(\mathrm{mm})],[\mathrm{t}(\mathrm{mm})])=394.92-44.1 \mathrm{t}+5.38 \mathrm{~h}-10.34 \mathrm{ht}+31.79 \mathrm{t}^{2} \\
& \varepsilon_{\mathrm{p}}([\mathrm{h}(\mathrm{mm})],[\mathrm{t}(\mathrm{mm})])=0.0152+0.0049 \mathrm{t}-0.0016 \mathrm{t}^{2}+0.00001 \mathrm{~h}
\end{aligned}
$$

The sensitivity of the ribbon bond temperature to the terms in RS model (15) is shown in Figure 17a. The sensitivity of equivalent plastic strain at the ribbon bond interface to the terms in RS model (16) is shown in Figure 17b. The constant 394.92 from (15) and 0.0152 from (16) has been excluded in the sensitivity plots in the Figure 17. 


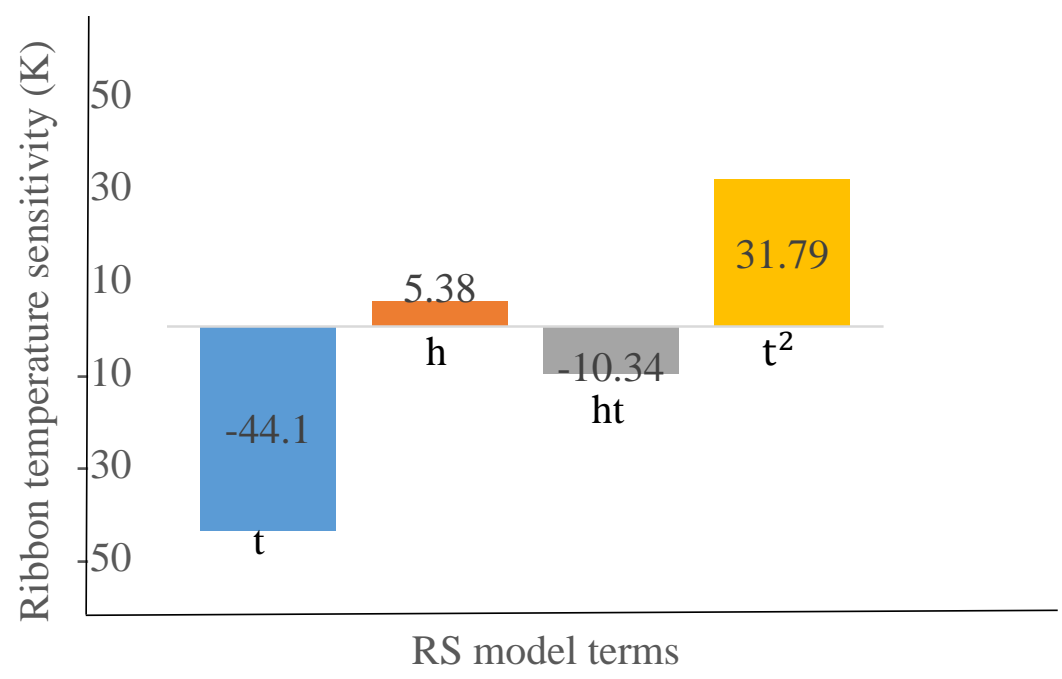

(a)

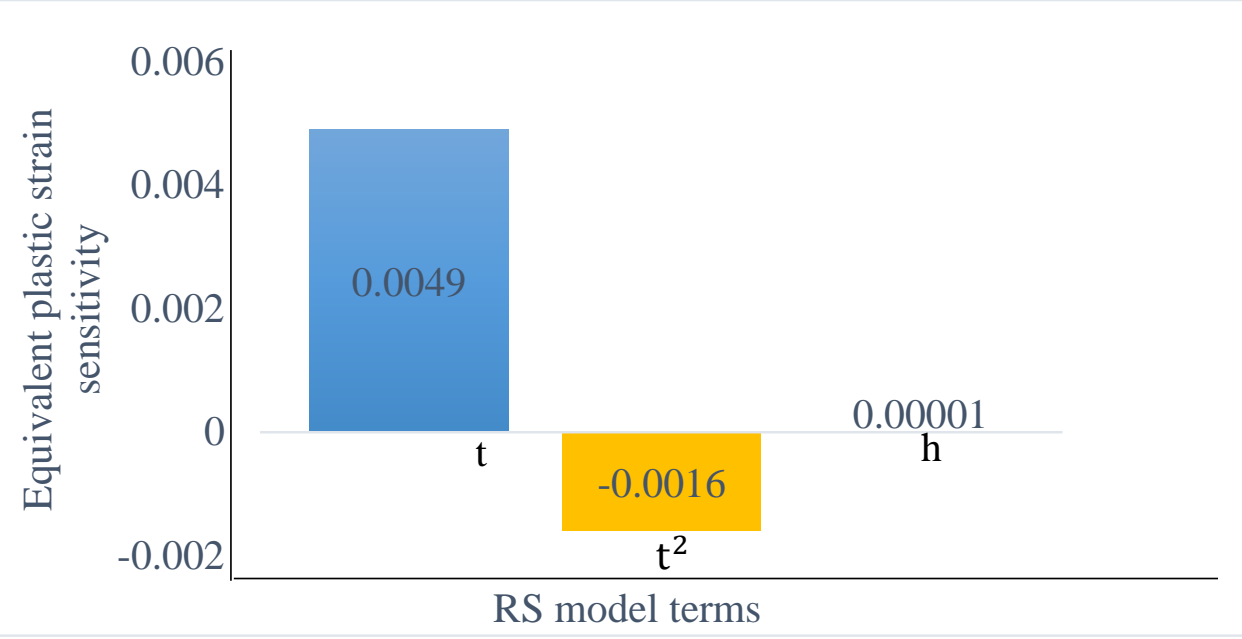

(b)

Figure 17. (a) The sensitivity of the ribbon bond temperature to the terms in RS model (15). (b) The sensitivity of the $\varepsilon_{p}^{e q v}$ at the ribbon bond interface to the terms in RS model (16)

The Figure $17 \mathrm{a}$ and $17 \mathrm{~b}$ helps to compare the sensitivity of the design variables i.e. how ribbon bond thickness and bond loop height affect and influence the temperature and the equivalent plastic strain RS models. It can be seen that the temperature and the equivalent plastic strain RS models are more sensitive to the ribbon bond thickness than bond loop height. This is also what was observed from the parametric study analysis. It can be said then that thickness is the most influential in the RS models (15) and (16) which are the normalised RS models for (12) and (13) respectively. One can see that a positive unit scaled increase in the ribbon bond thickness will reduce the temperature to about $44 \mathrm{~K}$ while similar unit scaled 
increment in bond loop height will increase the temperature only by $5 \mathrm{~K}$. Also such increment in thickness will increase the equivalent plastic strain by $0.49 \%$. On the other hand, such a positive unit scaled increment in loop height has almost no effect on the equivalent plastic strain. The quadratic term $t^{2}$ is also influential in both RS models. The interaction term (ht) between the loop height $\mathrm{h}$ and the ribbon bond thickness $t$ is also significant in the RS model for temperature (15) but no such interaction term for RS model for equivalent plastic strain (16).

The parametric study results showed that increasing the ribbon bond width and reducing the thickness will give a better reliability in terms of lower ribbon temperature and reduced stress and strain. However some constraints such as the need for new ultrasonic bonding wedge as the current and standard ribbon width is limited to $2 \mathrm{~mm}[1,14]$ will make this option less attractive. Furthermore, if the die size is a constraint (which always is as reduction in die size is often desirable), having a ribbon more than $2 \mathrm{~mm}$ in width is not appealing at the moment. Also current crowding effect at the bond interface will increase if a very small bond thickness is used. This could lead to highly localised differences in heat dissipation as well as the electric field strength increasing the impact of electro-migration [19]. Therefore, the design optimization of the ribbon bond should focus on ribbon bond width not more than $2 \mathrm{~mm}$ and varying the loop heights and thicknesses.

\section{Multi-objective Optimization}

Ribbon bonding performance can be optimized by changing its dimensions. For example, by reducing the thickness, the flexural rigidity can be increased therefore reducing stress and strain. However, this would increase the temperature as it has been shown above in the parametric analysis. To achieve an optimum design, the fatigue life needs to be increased by decreasing the plastic strain. At the same time the ribbon temperature needs to be kept within an acceptable range to avoid other failure mechanisms such as electro-migration or increasing the power device junction temperature beyond its safe operating area. This means that the optimization of ribbon bonding is a two-objective optimization problem with the plastic strain and the maximum temperature as the objective functions. Under both power and thermal cycling loading conditions, the stress/strain increases with the loop height and the ribbon bond thickness. This led to the conclusion that smaller wire thickness is more reliable than thicker wire with regards to flexure that is caused by thermal cycling [10]. However, the temperature of the ribbon increases as the bond loop height increases and significantly as the thickness decreases in the power cycling. Therefore, the two objectives are conflicting and simultaneous optimization of both objectives is not possible. This requires the use of a multi-objective algorithm to find the trade-off relationship between the two objectives.

For multi-objective optimization problem, the aim is to identify the optimal solutions in the form of a Pareto front. The Pareto front consists of a set of feasible non-dominated solutions in the feasible solution space. A solution is dominating another if and only if it is better than the latter for all the objectives. Any solution in the Pareto front is therefore worse off than any other solution in at least one objective. 
There are several multi-objective genetic algorithms GA such as vector evaluated GA (VEGA), Multi-objective GA (MOGA), Nondominated Sorting GA (NSGA) and many others [35]. The GA is developed through natural evolution process. It operates with the collection of chromosomes called population which are normally randomly initialized [35]. Using iterative search evolution, the populations are created and evaluated in the objective set. Subsequently, they help in identifying better and fitter solutions (parents) to create new chromosomes (offspring) through the process of crossover operation [35]. Sometimes random changes (mutation) is introduced into the characteristics of the chromosomes to enable escape from local optima. This is repeated until it converges (to a predefined value or number of generations) to a single solution or a set of multiple non-dominated solutions for the case of multi-objective optimization problems $[35,36]$. This study uses a multi-objective GA to find a trade -off relation between the objective of minimizing the ribbon bond temperature and also minimizing the plastic strain. The multi-objective analysis is performed as follow.

\subsection{Objectives, Constraints and Simulation process}

The multi-objective optimization procedure used in this study is as follow.

1. Determine the variables (upper and lower bounds), objectives and constraints

2. Perform design of experiment DoE using the Latin Hypercube sampling method to generate design points

3. Perform power and thermal cycling of the design points using ANSYS FEA

4. Generate a fitness function of the two objectives functions

5. Using the genetic algorithm solver in Matlab v.9.3 and selecting the tournament selection method to perform the multi-objective optimization and plot the Pareto front.

The multi-objective optimization problem in this study can be formulated as:

Objectives: Minimize $\left\{\begin{array}{c}\Delta \bar{\varepsilon}^{p} \\ \mathrm{~T}\end{array}\right.$

Subject to: maximum chip junction temperature $T_{j, \max } \leq 393 \mathrm{~K}$

Where $\mathrm{T}$ is the ribbon temperature and $\Delta \bar{\varepsilon}^{p}$ is the equivalent plastic strain range from the lifetime prediction model (10).

The design variable ranges is same as in the Table 8 .

The ribbon width and span are kept constant at $2 \mathrm{~mm}$ and $13.75 \mathrm{~mm}$ respectively.

The Matlab multi-objective GA solver uses the double vector population type and similar to the VEGA which approximate the Pareto-optimal set by a set of non-dominated solutions using crossover and mutation. The VEGA is the first multi-objective GA and straightforward to implement. Several solutions can be generated in one run. Only the selection mechanism needs to be modified per iteration. It has a fast convergence rate, though tends to converge to extreme of each objective [35]. This could be an advantage if such property is desirable in a particular problem. In VEGA, the population $P_{t}$ is divided randomly into $K$ equal sized subpopulations $P_{i} \ldots P_{K}(i=1,2 \ldots K)$ [35]. Where $K$ is the number of objectives. Then a fitness value is assigned to each solution in the subpopulation based on different objective function. The solution selection from these subpopulations is based on using proportional selection for 
crossover and mutation. This is repeated until convergence is reached. The procedure for VEGA is as described in [35]. This study uses the tournament selection method. In tournament selection method, each parent is selected by choosing individuals at random. To determine the number of individuals to be randomly selected, tournament size can be specified and then best individual would be chosen to be a parent.

\subsection{Multi-objective Optimization Results}

The population size used for the analysis is 50 for each generation. For reproduction, crossover fraction of 0.8 was used such that the cross-over operation generates $80 \%$ of next generation. Mutation generates the remaining individuals in the next generation. The tournament size chosen is 2 . Adaptive feasible mutation function with heuristic cross-over function were used. The heuristic cross-over function creates children that randomly lie on a line containing two parents. A small distance away from the parent with better fitness value and in the direction away from parent with worst fitness value.

Figure 18 is the Pareto optimal solutions plot of the two objectives functions after 200 generations of the search algorithm.

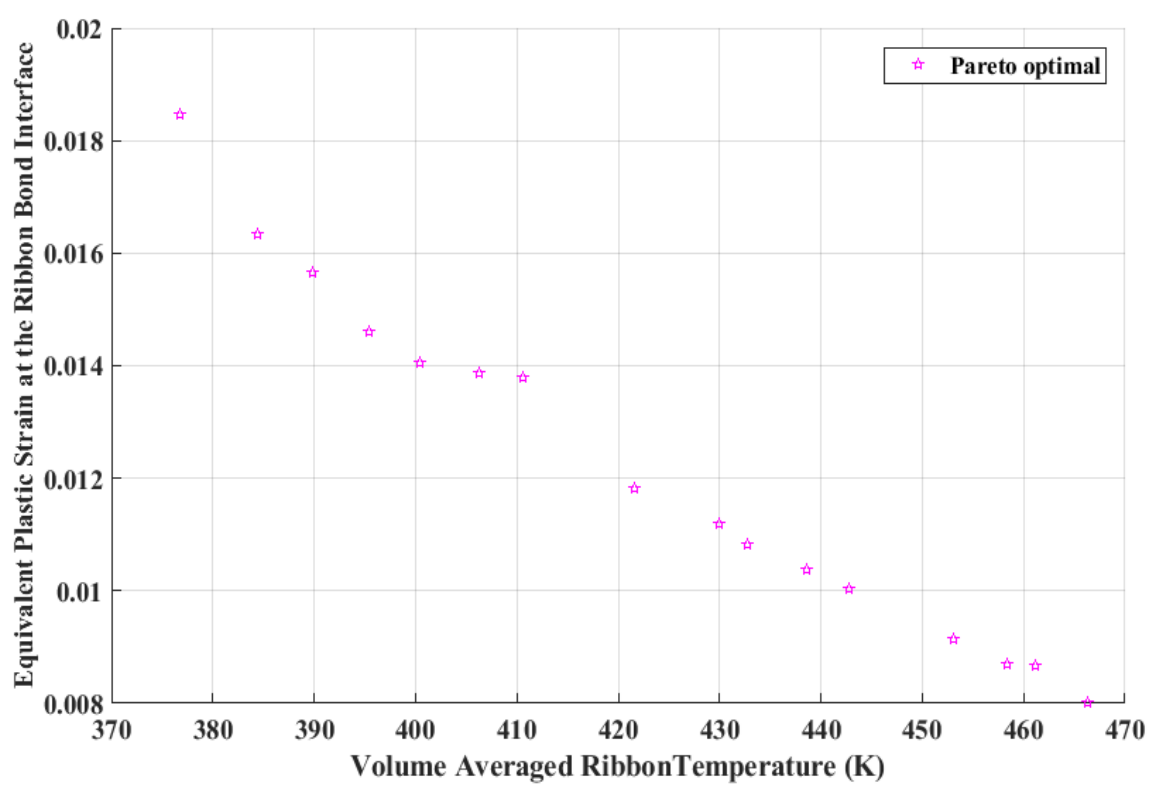

Figure 18. Pareto-front of the multi-objective optimization

Each point represents a Pareto optimum solution. The Pareto front have shown that if a solution improves in one objective, it degrades in the other. There exists no single solution that simultaneously optimises the two objectives and it is difficult to choose a particular solution. Therefore, a trade-off relationship can be established using the Pareto front plot. For example, reducing the equivalent plastic strain at ribbon bond interface from 0.0183 to 0.008 will result to increasing the maximum ribbon bond VWAT from $376 \mathrm{~K}$ to $468 \mathrm{~K}$. This means that $56 \%$ percent reduction in equivalent plastic strain will result in $25 \%$ increase in temperature. 
This plot therefore could be useful for designers to obtain a trade-off relationship between choosing ribbon thickness and bond loop height given a set of optimum solutions. However, some of the optimum solution will have some constraints hindering their selection. For example, ribbon bond thickness of $0.1 \mathrm{~mm}$ has been shown to have low stress and strain but higher temperature. If the ribbon width is increased to more than $2 \mathrm{~mm}$, the temperature will be reduced as have been mention earlier. Which means that a wider and thinner ribbon is an ideal solution. However, obtaining new bonding tools and miniaturisation of the power devices are some constraint that will hinder such selection. Therefore, while the Pareto optimal plot presented in this study is very essential in obtaining a trade-off value for any optimum solution, other factors such as manufacturability should also be considered in the final decision. Impact of such design choice on the overall power module should also be investigated. It has been observed in this study that increasing the population size will only increase the number of Pareto fronts. This has been investigated in this study by varying the number of population size from 20 to 100. Within this range, the average number of Pareto fronts increased from 7 to 37 . No significant change was observed in the Pareto front distribution for varying the crossover fraction for reproduction from 0 to 0.9 or increasing the tournament size.

Overall, the simulation time required to generate the Pareto optimal solutions depends on the number of variables, constraints and population size. The average simulation run time for population sizes between 20 and 100 observed in this study is 20 s.

\section{Conclusions}

This study has shown that if a single ribbon of $2000 \mu \mathrm{m}$ by $200 \mu \mathrm{m}$ is used to replace three $400 \mu \mathrm{m}$ diameter wires, the temperature in power electronic module i.e., chips, wires and ribbons will be almost identical. A lower temperature will be obtain in the ribbon, if copper is used and joule heating considered. The ribbon bond is less susceptible to fatigue failure than the conventional round wire bonds as a result of reduced flexure in the ribbon and increased surface area. The stress and strain distribution in the ribbon bond shows that bond lifting is most likely the dominant failure mechanism in ribbon bond whereas wire bond lift off is the dominant failure mechanism in the wire bond with the potential of heel crack failure because of wire flexing. The reliability of copper ribbon has been shown to be higher than aluminum ribbon and could be a potential replacement for the convectional wire bonds in IGBT power modules. This research has also found that in the simulation, it is important to consider the joule heating in the wire in addition to the heat dissipation in the chips during power cycling simulation. In the multi-objective optimization analysis, the trade-off relationship has been obtained which can be used as a guide for power module packaging designers.

\section{Acknowledgement}

Kenneth Chimezie Nwanoro is funded by the University of Greenwich's Vice Chancellor's PhD Scholarship Scheme.

\section{References}


[1] B. Ong, M. Helmy, and S. Chuah, "Heavy Al ribbon: An alternative solution for hybrid power packaging," IMAPS, Long Beach, CA, pp. 1-11, Nov., 2004

[2] W.Q. Ivy, P. Reid, R.E. Werner, and D. Doerr, "Automatic wedge bonding with ribbon wire for high frequency applications," $27^{\text {th }}$ IEEE/SEMI International electronics manufacturing technology symposium, IEMT, pp. 97-104, July, 2002.

[3] S. Jacques, R. Leroy and M. Lethiecq, "Impact of aluminium wire and ribbon bonding technologies on $D^{2} P A K$ package reliability during thermal cycling application," Microelectronics reliability, Elsevier, vol. 55, pp. 1821-1825.

[4] T.A. Buress, S.L. Campbell, C.L. Coomer, C.W. Ayers, A.A. Wereszczak, J.P. Cunningham, L.D. Marlino, L.E. Seiber and H.T. Lin, "Evaluation of the 2010 Toyota Prius Hybdrid Synergy Drive System", Oak Ridge National Laboratory, pp. 9-24, 2011, [Online] Available at: https://pdfs.semanticscholar.org/a5d4/3e8a28ae3bc3297ed449f18b42c817083ff9.pdf. $\quad$ Accessed: 21/11/2017.

[5] K.C. Nwanoro, H. Lu, C. Yin, and C. Bailey, "Computer simulation of the reliability of wire bonds and ribbon bonds in power electronics module" THERMINIC 2017, pp. 1-6.

[6] Y. Celnikier, L. Dupont, E. Herve, G. Coquery and L. Benabou, "Optimization of wire connections design for power electronics, Journal of Microelectronics reliability, vol. 51, no. 9-11, pp. 1892-1897, Elsevier, 2011

[7] M. Held, P. Jacob, G. Nicoletti, P. Scacco, and M. -H. Poech, "Fast power cycling test for IGBT modules in traction application”, Proc. IEEE Int. Conf. Power Electron. Drive Systems, vol. pp. 425-430, May 1997.

[8] S. Ramminger, G. Mitic, P. Türkes and G. Wachutka, "Thermo-mechanical simulation of wire bonding joints in power modules," International conference on modelling and simulation of microsystems, San Juan, Puerto, pp. 483-486, April, 1999.

[9] M. Ciappa, "Selected failure mechanism of modern power modules," Microelectronics reliability, vol. 42, no. 4-5, pp. 653-667, May, 2002.

[10] K.N. Meyyappan, "Failure prediction of wire bonds due to flexure," University of Maryland; pp. 27-34, 2004.

[11] Powerex Corporation. (2013). Datasheet of NFH-series IGBT module (150amperes/1200volts) [Online]. Available: ttp://www.pwrx.com/pwrx/docs/cm150du-24nfh.pdf. Accessed on 12/7/2017.

[12] ABB Switzerland Ltd. (2013). Datasheet of IGBT-Die 5SMY $12 \mathrm{M} 1280$ [online]. Available:https://library.e.abb.com/public/6e0cca10bb77aad9c1257e0e0038c619/5SMY\%2012M1280 5SYA\%201322-04\%2012\%2014.pdf. Accessed on 9/11/2017.

[13]ABB Switzerland Ltd. (2013). Datasheet of Diode-Die 5SLY $12 \mathrm{~J} 1200$ [online].Available:https://library.e.abb.com/public/b20d46629549be30c1257e0e003a20fe/5SLY\%2012 J1200_5SYA\%201684-03\%2012\%2014.pdf. Accessed on 9/11/2017.

[14]Heraeus, "Bonding Wires for Semiconductor Technology", Brochure, pp. 20. [Online] Available at: https://www.heraeus.com/media/media/het/doc het/products and solutions het documents/bonding wires documents/Brochure Bonding Wire.pdf. Accessed: 20/11/2017.

[15] L.R. GopiReddy, L.M. Tolbert, and B. Ozpineci, "Power cycle testing of power switches: A literature survey" IEEE Trans. On Power electronics, vol. 30, No. 5, pp. 2465-2473, 2015.

[16] F. Auerback and A. Lenniger, "Power-cycling-stability of IGBT modules" IEEE Ind. App. Soc., Annual meeting, pp. 1248-1252, 1997.

[17] T-Y. Hung, L-L.Liao, C.C. Wang, W.H. Chi and K-N. Chiang, "Life prediction of high-cycle fatigue in aluminum bonding wires under power cycling test," IEEE Transactions on Device and Materials Reliability, vol.14, no. 1, pp. 484-492, March, 2014.

[18] S. Ramminger, N. Seliger and G. Wachutka, "Reliability Model for Al Wire Bonds subjected to Heel Crack Failures," Micro. Reliability, vol. 40, pp. 1521-1525, 2000.

[19] L.L. Liao, T.Y. Hung, C.K. Liu, W. Li, M.J. Dai and K.N. Chiang, "Electro-thermal finite element analysis and verification of power module with aluminum wire” Microelect. Eng., pp. 114-120, 2014, Elsevier.

[20] C. Qian, A.M. Gheitaghy, J. Fan, H. Tang, B. Sun, H. Ye, and G. Zhang, "Thermal management on IGBT power electronic devices and modules" IEEE Access, no. 99, 2018, pp. 1-16.

[21] R. Skuriat, J.F. Lip, A. Agyakwa, N. Mattey, P. Evans, and C.M. Johnson, "Degradation of thermal interface materials for high-temperature power electronics applications" Microelectronics Reliability, vol. 53, no. 12, pp.1933-1942, 2013.

[22] R. Dudek, R. Doring, S. Rzepka, C. Ehrhardt, M. Gunther, and M. Haag, "Electro-thermo-mechanical analysis on silver sinted IGBT-module reliability in power cycling", EuroSimE 2015, pp. 1-8. 
[23] B. Rodgers, J. Punch, and J. Jarvis, "Finite Element Modelling of a BGA Package Subjected to Thermal and Power Cycling" Int. Society Conference on Thermal Phenomena, IEEE, pp. 993-1000, 2002.

[24] P. Rajaguru, H. Lu and C. Bailey, "Application of nonlinear fatigue damage models in power electronic module wirebond structure under various amplitude loadings, Journal of advances in manufacturing, vol. 2, no. 3, pp. 239-250, 2014

[25] A. Wright, A. Schletz and A. Pichler, "Thermo-mechanical simulation of plastic deformation during temperature cycling of bond wires for power electronic module," $15^{\text {th }}$ International conference on thermal, mechanical and multi-physics simulation and experiments in microelectronics and microsystems, EuroSimE, pp. 1-5, 2014.

[26] A. Zéanh, O. Dalverny, M. Karama, E. Woirgard, S. Azzopardi, A. Bouzourene, J. Cassut, and M. Mermet-Guyennet, "Thermomechanical Modelling and Reliability Study of an IGBT Module for an Aeronautical Application” pp.2, EuroSimE, 2008.

[27] G.Z. Wang, Z.N. Cheng, K. Becker and J. Wilde, "Applying Anand model to represent the viscoplastic deformation behavior of solder alloys," ASME Journal of Electronic packaging, vol. 123, pp.247-253, 2001.

[28] S.S. Manson, “Thermal stress and Low Cycle Fatigue”, McGraw Hill 1966

[29] K. Weinberg and W.H. Müller, "A strategy for damage assessment of thermally stressed copper vias in microelectronic printed circuit boards", Microelectronics Reliability, vol. 48, No. 1, pp. 68-82, 2008.

[30] N.V. Chidambaram, "A numerical and experimental study of temperature cycle wire bond failure," 41 st ECTE, pp. 877-882, 1991.

[31] T.M.I.F. Junior and R. Magnabosco, "Evaluation of methods for estimating fatigue properties applied to stainless steels and aluminum alloys," Tecnol Metal Meter Mineracao, vol. 9, No. 4, pp. 284-293, 2012.

[32] M.D. McKay, W.J. Conover, R.J. Beckman, "A comparison of the three methods for selecting values of input variables in the analysis of output from a computer code", Technometrics vol. 21, no 2, 1979, pp. 239-249.

[33] S.S. Stoyanov, C. Bailey, and M. Desmulliez, "Optimization modelling for thermal fatigue reliability of lead-free interconnects in fine-pitch chip packaging," Soldering and Surface Mount Technology, vol. 2, no. 1, pp. 11-24, 2009

[34] Vanderplaats. VisualDoc. "Design optimization software version 5.1. Theoretical manual.” pp. 35-51, Vanderplaats R\&D Colorado Springs, 2005.

[35] A. Konak, D.W. Coit and A.E. Smith, "Multi-objective optimization using genetic algorithms: A tutorial," Reliability Eng. And System Safety, vol. 91, pp. 992-1007, 2006.

[36] D.F. Jones, S.K. Mirrazavi and M. Tamiz, "Multiobjective meta-heuristics: an overview of the current state-of-the-art,” European Journal of Operational Research, vol. 137, pp. 1-9, 2002. 